\title{
NUEVA INFORMACIÓN SOBRE LA PINTURA DE CRISTÓBAL DE VILLALPANDO EN GUATEMALA
}

\author{
Luis Luján MuÑoz.
}

\section{Introducción}

Es evidente que existieron profundas relaciones artísticas entre la Nueva España y el Reino de Guatemala en la época colonial. Estos vínculos parecen hacerse más notorios en la pintura que, procedente de México, llegaba a Guatemala y en la escultura finamente estofada que, de la ciudad de Santiago de Guatemala, iba a distintos lugares de la Nueva España, pero particularmente a la capital del virreinato y a Puebla de los Ángeles. En este trabajo hemos reunido la nueva información que poseemos acerca de la pintura de Cristóbal de Villalpando en Guatemala, tanto por ser uno de los más interesantes artistas novohispanos, como por publicarse por primera vez el texto íntegro del contrato entre dicho artista y el convento de San Francisco el Grande en Santiago de Guatemala, para realizar cuarenta y nueve obras, ${ }^{1}$ así como dos pinturas más firmadas por Villalpando y otras dos atribuibles a éste. Asimismo, serán publicadas por primera vez íntegramente las catorce pinturas sobrevivientes de la Vida de San Francisco de Asís ya que nuestro recordado maestro el doctor Francisco de la Maza, no pudo incluirlas en su valiosa obra El pintor Cristóbal de Villalpando. ${ }^{2}$

No está por demás recordar la confusión que en Guatemala se creó, alrededor del mito de un pintor llamado Francisco de Villalpando, nacido en Santiago de Guatemala, según Víctor Miguel Díaz, quien inició esta invención en 1920 y la llevó a su mayor exageración en su obra Las Bellas Artes en Guatemala, publicada en $1934,{ }^{3}$ seguido entusiastamente por el

1 Deseamos testimoniar nuestro agradecimiento a Jorge Alberto Manrique por habernos facilitado la obtención del contrato aludiclo, así como a Amada Martínez quien nos proporcionara las copias electromecánicas del mismo, ambos estimados amigos del Instituto de Investigaciones Estéticas de la UNAM.

2 De la Maza, Francisco, El pintor Cristóbal de Villalpando, México, Instituto Nacional de Antropología e Historia, 1964.

${ }^{3}$ Primeramente lo hizo en Diario de Centro América (11 noviembre 1920) en "Ctónicas viejas", con el subtítulo "El convento de San Francisco" posteriormente, en 1927, lo ratificó en La romántica ciudad colonial (Guatemala, Tipografía Sánchez y de Guise), que es una reproducción de los artículos mencionados antes. Los datos bibliográficos de su otra obra mencionada son los siguientes: Las Bellas Artes en Guatemala Guatemala, Tipografía Nacional, 1934. 
Lic. J Antonio Villacorta, en varias publicaciones pero principalmente en su obra Historia de la Capitanía General de Guatemala, salida de prensas en 1942: Esperamos, sin embargo, que esta leyenda a la que todavía se alude algunas veces en Guatemala, por carencia de información, ingenuidad y algunas veces mala fe, tenga vida menos larga que la del pintor Rodrigo de Cifuentes en México, en donde todavía lo hemos oído mencionar esporádicamente, pese a las reiteradas demostraciones acerca de su inexistencia.

E1 concierto o contrato para realizar por parte de Cristóbal de Villalpando cuarenta y nueve pinturas para el convento Grande de San Francisco en la ciudad de Guatemala, parecen indicar que Villalpando fue el pintor mexicảno con más obras en Guatemala. Efectivamente, ni Juan Correa, ni Pedro Ramírez, ni siquiera el prolífico Miguel de Cabrera enviaron a Guatemala tantas obras, pese a que no estimamos imposible encontrar otras obras pictóricas de artistas mexicanos, tanto en la actual Guatemala, como quizás en la vieja Ciudad Real de Chiapas, Comayagua en Honduras, San Salvador en El Salvador y León en Nicaragua, que fueran las principales ciudades del Reino de Guatemala, aparte naturalmente de Santiago de Guatemala.

Igual cosa podremos decir de la obra del propio Villalpando, en el sentido que acaso fuera dable localizar nuevas obras hasta ahora desconocidas e identificar las faltantes del subido número de cuarenta y nueve o algunas otras. En todo caso, en el Apéndice Documental de este trabajo, incluiremos completo por primera vez el texto del concierto para realizar las aludidas pinturas de la Vida de San Francisco de Asís. ${ }^{5}$

\section{Vida y obra de Cristóbal de Villatpando vistas desde Guatemala}

No pretendemos aquí intentar hacer una biografía y un análisis exhaustivo de la vida y obra de este artista, respectivamente, porque ello sería poco menos que inútil, sino apenas dar los datos esenciales de su biografía, así como sus características estéticas más esenciales, para poderlo enmarcar en relación a las pinturas que se encuentran en Guatemala, si bien incorporaremos algún nuevo dato sobre sus obras de reciente publicación, como es su actividad de escultor.

${ }^{4}$ Guatemala, Tipografía Nacional, 1942

5 Archivo de Notarías de la Ciudad de México. Notario Martín del Río, no. 563 Libro del año 1691 , fols $415-16$ 
Siguiendo las informaciones fundamentales de Toussaint ${ }^{6}$ y de la $\mathrm{Maza}^{7}$ podemos ver que Cristóbal de Villalpando nació en la ciudad de México hacia 1649 y falleció en ella el 20 de agosto de 1714. Casó el 2 de junio de 1669 con María de Mendoza, también natural y vecina de dicha ciudad, hija al parecer del pintor poblano Diego de Mendoza y hermana, asimismo, de otro pintor llamado Miguel de Mendoza. Tuvieron dos hijos: Carlos de Villalpando, nacido el 30 de agosto de 1680 y que sería pintor como su padre al correr del tiempo y otro que llevó el mismo nombre de su progenitor y que naciera el 5 de febrero de 1690.

$\mathrm{Su}$ vida profesional parece haber sido muy intensa, habiendo desempeñado numerosas veces el cargo de Veedor del gremio de pintores, doradores y entalladores, lo que lo hizo participar en las actividades de carácter profesional que implicaba este cargo directivo, así como las habituales de firmar contratos para la enseñanza de la pintura con aprendices y la de examinar a quienes deseaban convertirse en maestros. ${ }^{8}$

Respecto de su obra se menciona la fecha de 1675 como la inicial conocida, para cuando firma unos lienzos del retablo de Huaquechula, Puebla. Para 1684 debió tener el suficiente prestigio para que se le encargasen los lienzos murales de la sacristía de la catedral de México, cuyo éxito lo hace ser contratado para hacer otro de grandes dimensiones en la sacristía de la catedral de Guadalajara al año siguiente. En 1687 concluye el magnífico mural del intradós de la cúpula de la catedral de Puebla, siendo aproximadamente la década entre 1680 a 1690 la de su mayor fama y florecimiento. Por ello no debe extrañarnos que en septiembre de 1691 se hubiera firmado el contrato con el convento franciscano de Guatemala para realizar los cuarenta y nueve lienzos antes mencionados, entre los que estaban incluídos:

... Treinta y tres liensos grandes y diez y seis chicos con la vida de N.S.P.S. Franco, conforme la del Claustro del Convento principal de esta ciudad de México, de suerte que todos sean cuarenta y nueve liensos ...?

6 Toussaint, Manuel, Pintura colonial en México México. Imptenta Universitaria, 1965 p. 143 .

T De la Maza, op cit

${ }^{8}$ Curiosamente entre los maestros examinados se menciona que el 22 de abril de 1698, ".... examinaron a Alfonso Álvarez de Urrutia, vecino de Santiago de Guatemala y residente en México, oficial de pintor y lo aprobaron". Artista guatemalteco de quien carecemos de alguna información adicional. De la Maza, 1964, p. 8.

${ }^{9}$ Ya veremos más adelante que ptobablemente los treinta y tres grandes pudieron set los de la serie de la Vida de San Francisco de Asis: 
En 1694 hace un Apostolado que se encuentra en el Museo de Querétaro así como las pinturas para un retablo de la iglesia de San Francisco en dicha ciudad. Al año siguiente trabaja una de sus más bellas e importantes obras como es la "vista de la Plaza Mayor de México". Posteriormente, entre sus obras más notorias se encuentran las hechas para la iglesia de Guadalupe en Zacatecas y la serie de la vida de San Ignacio de Loyola que decoran el claustro principal del colegio jesuítico de Tepotzotlán, las únicas comparables en número, ya que son veintitrés, a las de Guatemala.

Se ha afirmado que Villalpando también fue arquitecto, habiendo sido el constructor de la iglesia de San Agustín en la ciudad de México, obra inaugurada en 1691 y que de la Maza estima como muy posible. ${ }^{10}$ Asimismo, construyó varios arcos triunfales de arquitectura efímera como los hechos para el ingreso del Conde de Mónclova en 1686 y el del virrey Conde de Alburquerque, en 1702. Recientemente Efraín Castro Morales ha publicado un documento en donde se desprende que Villalpando también fue escultor, ${ }^{11}$ pues el 31 de mayo de 1701 fue propuesta a la Unión y Confraternidad del Oratorio de San Felipe Neri de México, un Ecce Homo, de talla y estatura natural, que había realizado para sí mismo con todo esmero y particular cuidado Cristóbal de Villalpando, ${ }^{12}$ para que permaneciera perpetuamente en dicha entidad, aunque desgraciadamente no se ha conservado la escultura.

Desde el punto de vista estilistico a Villalpando le correspondió vivir en plena época barroca, siendo por consiguiente un pintor que desarrolló su obra de acuerdo con los postulados de dicho estilo. E1 doctor Diego Angulo Iñiguez indica que la obra de este pintor principia cuando el tenebrismo de Francisco de Zurbarán (1598-1664) ha pasado de moda y son Bartolomé Esteban Murillo (1618-1682) y un poco después Juan de Valdés Leal (1622-1690), los que dominan la escuela sevillana que tanto influjo ejercería en Hispanoamérica, subrayando que es este último artista quien parece haber tenido mayor influencia en el novohispano, particularmente en su despreocupación por el dibujo, notándose al propio tiempo la influencia de Pedro Pablo Rubens (1577-1640). Mediante sus populares grabados, que tanto circularan en el ambiente hispánico.

10 De la Maza, 1964, p. 12.

11 Castro Morales, Efraín, "Una escultura de Cristóbal de Villalpando". En Boletin de Monumentos Históricos del Instituto Nacional de Antropología e Historia, no. 3. México, 1979, pp. 9-14.

12 Se le dieron a Villalpando $\$ 200$, no por compra sino "por vía de agasajo", al donar la aludida escultura. 
Para Francisco de la Maza, se nota una curva muy definida en la obra de Villalpando: en sus inicios austeridad y severidad, en su apogeo su pintura es fastuosa y luminosa, para volverse grave y mesurada al final de su vida. En todo caso se nota en Villalpando una gran desigualdad, pues en su amplia obra nos encontramos con temas tratados magníficamente, al propio tiempo que otros, en cambio, son trabajados muy mediocremente debido, quizás, a la premura del tiempo en entregar las obras encargadas. Como pintor barroco adopta entusiastamente algunos temas impulsados por la Contrarreforma, tales como la Inmaculada Concepción, la exaltación de los Sacramentos, primordialmente el de la Eucaristía, así como devociones nuevas como es el culto hacia San José, tan entusiastamente seguido por Santa Teresa de Jesús. Además, usaba ampliamente de determinadas actitudes o situaciones, tales como el martirio y el éxtasis y el sentido de lo heroico, todo ello lleno del dinamismo barroco que le concede tanta importancia a los ropajes de sus personajes hasta convertirlos en un elemento primordial en la composición pictórica.

Para dar por terminadas estas líneas relacionadas con la obra de Villalpando debemos decir, inspirados en la observación de sus pinturas, que se percibe en ellas una composición muchas veces ilógica por lo confuso de sus planes y por el no siempre claro señalamiento de los puntos focales. Se nota también un desconocimiento de la anatomía humana perceptible sobre todo en los desnudos, en los que lo mejor tratado son las piernas, más pictóricamente vistas que ceñidas a la realidad anatómica y lo más deficiente resultan ser las manos, casi siempre pobremente pintadas y poco expresivas. Por otra parte, sus figuras humanas se ven poco perfiladas no dando impresión de solidez en la técnica pictórica: usa muy poco del escorzo y curiosamente las miradas parecen huír de ver directamente al espectador, con excepción casi única de sus dos autorretratos. ${ }^{13}$ $\mathrm{Su}$ colorido es rico en determinadas pinturas pero en otras en cambio es muy poco variado utilizando básicamente el gris, blanco y negro, pero todo pasado por marrón, lo que resulta particularmente ser cierto para la serie de la vida de San Francisco que se encuentra en Guatemala, aunque quizás al limpiarse y restaurarse aparezca un colorido más rico.

Naturalmente, como todos los pintores de la época, aun los más grandes, se ve muy influído por grabados y pinturas de sus antecesores y con-

\footnotetext{
${ }^{13}$ Curiosamente, no parece Cristóbal de Villalpando haber hecho retratos Estos dos autorretratos, correspondería, el primero, a una de las pinturas de la sacristía de la catedral de México, es decir de 1685 y el otro incluído en la setie franciscana de Guatemala, hacia 1692, es decit cuando el artista tenía aproximadamente, 36 y 43 años, respectivamente; es decir en la plenitud de su vida.
} 
temporáneos, que facilitaban su tarea, siempre constreñidos por el tiempo de entrega. Logra Villalpando, sin embargo, excepcionales aciertos en el tratamiento de ropajes, joyas y orfebrería que dan una suntuosidad barroca muy bella, como en sus hermosas figuras de arcángeles, pero que acaso le sirven para evadir las soluciones de una correcta anatomía.

III. La secuencia de la vida de San Francisco de Asís del convento grande franciscano de Santiago de Guatemala

Ya hemos dicho que así como Guatemala enviaba a México finas esculturas estofadas, recibía, en cambio, pinturas de las figuras artísticas más conocidas tales como Nicolás Rodríguez Juárez, Juan Correa y Cristóbal de Villalpando en el siglo XVII y José de Páez y Miguel Cabrera en el siglo XVIII, la mayor parte de ellas firmadas, porque probablemente los clientes guatemaltecos exigirían la firma que autenticar la calidad de la obra y el prestigio del autor (sin que lo anterior quiera significar que no existan pinturas anónimas de artistas mexicanos, como debieron haber aunque en menor escala, pinturas españolas, cuyo mejor ejemplo vendría a ser el "apostolado" de Zurbarán). Sin embargo, la publicación del contrato entre Villalpando y el convento de San Francisco de Guatemala nos enfrenta al problema de que muchas de estas pinturas parecen haberse perdido con el transcurso del tiempo y sobre todo a causa de los terremotos, como lo ejemplifica el hecho que de las cuarenta y nueve obras de Villalpando apenas subsisten diecinueve o veinte, es decir apróximadamente una tercera parte de ellas. ¿Habrá sido así con los otros pintores? En todo caso se puede apreciar que fue la orden franciscana la que parece haber tenido más relación con la pintura mexicana, como lo demuestran los ejemplos del convento y de la iglesia de San Francisco en la Antigua Guatemala con los Villalpando, además que conserva un lienzo anónimo con el Cristo de Ixmiquilpan y la iglesia de Concepción, Ciudad Vieja, posee varios Correas. ${ }^{14}$

Como deciamos antes, en la actualidad conocemos dieciséis pinturas de Villalpando que corresponden, once al Museo Colonial en la Antigua Guatemala, tres a la iglesia de San Francisco en la Nueva Guatemala, que no han sido descritos antes, los que forman todos ellos parte de la serie

1* Berlín, Heintich, "Pintura colonial mexicana en Guatemala" en Anales de la Sociedad de Geogratia e Historia de Guatenala, tomo XXVI, no 1 (matzo de 1952) Guatemala, Tipografía Nacional pp. 118-28. 
de la Vida de San Francisco de Asis ${ }^{15}$ y a los que nos referiremos especificamente más adelante; asimismo, una Virgen de Guadalupe que se encuentra en la iglesia de San Jerónimo, Baja Verapaz, que formaba parte de la provincia dominica en Guatemala y la Muerte de San José en dos colecciones privadas, ambas prácticamente nunca descritas, ni estudiadas, y otras dos más atribuibles. Comencemos a hablar de la colección de la "Vida de San Francisco de Asís".

Hemos afirmado, y no quisiéramos recordarlo, que estas pinturas fueron las que dieron origen al mito de Francisco dé Villalpando. Gracias a la ayuda de nuestro maestro Francisco de la Maza pudimos conocer de la información inicial acerca de este contrato mediante el cual Cristóbal de Villalpando se comprometía a realizar esta serie de la vida de San Francisco, que creemos corresponde a los que en dicho instrumento legal se mencionan como treinta y tres lienzos grandes, habiéndose destruído o extraviado los otros dieciséis chicos que debieron ser de diversos temas ${ }^{16}$ Afirmamos lo anterior porque observando cuidadosamente las ruinas del convento de San Francisco en Antigua Guatemala, estudiamos los espacios posibles para colocar los lienzos con las dimensiones conocidas de los catorce sobrevivientes y dan casi con absoluta certeza el número de treinta y tres, existiendo apenas la duda de un espacio, que más bien pudo haber sido llenado con algún otro motivo decorativo, de manera que creemos poder afirmar que en el claustro bajo de San Francisco hubo quince pinturas con la vida de San Francisco con toda certeza y tres más muy posiblemente, lo que haría un total de dieciocho y de catorce en el claustro alto, cuyos espacios son seguros y uno dudoso que sumarían un total de treinta y tres que debió constituir un conjunto impresionante de pinturas, que debieron darle justificado orgullo a la orden franciscana.

Pasemos ahora a estudiar el documento, desgraciadamente no tan explícito como hubiéramos querido, pues no especifica los temas de las cua-

is Parece haberse extraviado una pintura de las que subsistían en la iglesia de Sañ Francisco de la ciudad de Guatemala, quizás en los últimos 50 años. Estas 3 pinturas nunca han sido descritas.

${ }^{16}$ Fernández, Jesús en: "Estudios sobre la Exposición, publicado en La Semana Católica. Nos. 259-263, correspondientes a mayo y junio de 1897 y editadas por Ricardo Toledo Palomo en Anales de la Sociedad de Geografía e Historia de Guatemala Tomo XXXII (enero a diciembre de 1950) Guatemala Tipogtafía Nacional pp. 112-30, manifiesta creer que Villalpando (a quien no adjudica ningún nombre de pila) era guatemalteco y que pintó 40 cuadros sobre la vida de San Francisco, equivocándose hontadamente en lo primero por desconocimiento de las fuentes bibliogtáficas peto sin añadir lo que la imaginación de Díaz y Villacorta pusieron después. Asimismo, con buen ctiterio ratifica la originalidad del "Apostolado" de Zurbarấn en la iglesia de Santo Domingo. 
renta pinturas, concretándose a señalar, como ya hemos dicho antes, que eran treinta y tres grandes y dieciséis chicos, lo que incluso daría la posibilidad que los cuarenta y nueve se refirieran a la vida de San Francisco de Asís, situación que sin embargo no creemos sea la verdadera. El contrato está firmado por el artista Cristóbal de Villalpando y por el mercader Francisco Gómez del Corral en representación del provincial de la orden franciscana en Guatemala, Fray Francisco de Suassa y Otálora, según un croquis que éste último remitiera a México en donde se especificarían las dimensiones y probablemente los temas a desarrollar, el cual fue firmado por ambas partes. ${ }^{17}$

Previa a la escritura se menciona una carta firmada por el Padre Suassa el 25 de agosto, en la que daba la orden de que se efectuara el concierto o contrato. La escritura fue firmada el 20 de septiembre de 1691, para ser entregados un año después, es decir el 20 de septiembre de 1692, lo cual nos parece un período harto corto para concluir cuarenta nueve pinturas, treinta $\mathrm{y}$ tres de ellas de grandes dimensiones, pues nos daria un promedio de un pintura por semana, lo que no sería posible de hacer si no fuera con el concurso de un taller $u$ obrador bien organizado con buena cantidad de oficiales y aprendices. Lo anterior en cierto modo no lo esconde Villalpando porque dentro del importe de su paga menciona que esta deberá incluir la paga de oficiales. En todo caso es evidente que estas obras de Villalpando se tratarían de pinturas de taller en las que él intervendría, acaso, para darle inicialmente la composición y luego los toques finales, pues se trataba de reproducir las que se encontraban en el convento principal de la ciudad de México, que según don Manuel Toussaint, citando al cronista fray Agustín Vetancurt en su Teatro mexicano:

Los claustros bajos están adornados con lienzos grandes del pincel famoso del Baltazar de Chávez, en que se registra toda la vida de N.P. San Francisco y entre cuadro y cuadro una tarja que tienen dos ángeles en que está escrita la historia de cada lienzo en romance lacónico y suscinto. $^{18}$

17 Según Fray Francisco Vásquez, en Crónica de la Provincia del Santísimo Nombre de Jesús de Guatemala. Guatemala, Sociedad de Geografía e Historia, 1944. Tomo IV, p. 175, Fray Francisco de Suaza, Zuaza o Cuaza, murió siendo sacristán de la capilla de Nuestra Señora de Loreto, en 1700. Fray Suaza era vizcaíno, desempeñó cargos importantes dentro de la obra en la que tomó el hábito en 1657, en Santiago de Guatemala. Dominaba los idiomas quiché, cakchiquel y zutuhil. Idem. p. 307.

18 Toussaint, 1965, p. 90. 
Es decir, que era obra de Baltasar de Echave Ibía, ${ }^{19}$ pero desgraciadamente no queda absolutamente nada de esta serie de pinturas que nos serviría para comparar con las que existen en Guatemala, pese a que todavía estaban a mediados del siglo pasado. ${ }^{20}$ Tampoco sabemos si finalmente Villalpando cumplió con el plazo estipulado, pero nos inclinamos a creer, si fueron montados y colocados en 1695, que posiblemente los entregó hasta muy entrado el año 1693 o principios de 1694, lo que daría un tiempo prudencial de un poco más de un año para hacer los bastidores, tallar las molduras de los marcos y posteriormente dorarlos, aunque tampoco sería imposible que teniendo ya las dimensiones en Guatemala hubiesen preparado con antelación marcos y bastidores, lo cual nos parece sin embargo algo arriesgado. Al hablar de las obras emprendidas después de los terremotos de febrero de 1689 y específicamente al referirse a la actividad de fray Francisco de Suaza como Ministro Provincial, en el trienio de febrero de 1688 a marzo de 1691, seguido de fray Nicolás de Quiñónez, de 1691 a febrero de 1694, cuando es substituído por fray Francisco de Ledesma, a quien le corresponde colocar los cuadros de Villalpando en su sitio. Dice Vázquez al respecto

$\mathrm{Y}$ en fabricar los cuatro claustros principales de abajo, de medio cañón muy hermosos y lucidos, que después se adornaron con cuadros de excelente pintura mexicana, de toda la vida de nuestro Padre San Francisco guarnecidos con muy lucidos marcos dorados. ${ }^{21}$

Según el contrato el valor que se pagaría a Villalpando por las cuarenta $y$ nueve pinturas, que incluian:

... travaxo, materiales, lienso y paga de oficiales está concertada dicha obra en dos mill nuevecientos y sesenta pesos.

Dicha cantidad se pagaría por parte de Francisco Gómez del Corral de la siguiente forma: $\$ 1,000$ pesos adelantados, otros $\$ 500$ al transcurrir el plazo de dicho trabajo y al concluir el mismo se le proporcionarían los restantes $\$ 1,460$. Desgraciadamente no se informa cuánto de esa cantidad

19 Toussaint, 1965. Con su acostumbrada penetración establece la existencia de tres pintores de la dinastía Echave, homónimos entre sí y que fueton abuelo, padre e hijo: Baltasar de Echave Orio (1548-1620), Baltasar de Echave Ibía (1610-1640) y Baltasar de Echave Rioja (1632-1682).

20 De la Maza, 1964, p. 143, dice que José Bernardo Couto en su Diálogo de la pintura en México, escrito en 1860, los vio colocados en su sitio original.

21 Vázquez, 1944. p. 390. 
correspondía a los treinta y tres lienzos grandes, ni a los dieciséis pequeños. Se estipulaba, además, que el lote de pinturas sería:

... entregado con toda perfección y según arte, la obra compuesta de los liensos de pincel..., aparejando los liensos con toda perfección según arte para su permanencia y dándole al pincel todo el primor que pudiera para su realsse y mexor perfección, estando todo ello a contento y satisfacción de dos maestros que lo entiendan.

Se señalaba que si la obra se consideraba defectuosa o no era entregada a tiempo el dicho Francisco Gómez del Corral estaba autorizado para contratar a otros pintores y Villalpando pagar lo que fuere necesario, con lo que quedaba a cubierto el convento de San Francisco de que se le cumpliese el plazo y la calidad de la obra. Asimismo, aunque no está estipulado, parece haber tenido Villalpando la obligación de firmar casi todas sus pinturas, lo cual por otra parte era bastante frecuente en él pues son raras en las que no consignó su nombre, si bien desgraciadamente casi nunca las fechaba.

Pasemos ahora a hacer una breve descripción de las catorce pinturas sobrevivientes de la vida de San Francisco de Asís, aunque previamente haremos una breve historia de las vicisitudes que éstas han pasado.

Ya hemos visto que probablemente con los terremotos de 1773 éstas debieron sufrir daños considerables, desconociendo por consiguiente cuántas existían en el convento franciscano de la ciudad de Guatemala para los terremotos de $1917-18 .^{22}$ En todo caso diez de ellas fueron cedidas o vendidas al artista español Justo de Gandarias, las que fueron adquiridas, según hemos visto antes, por el gobierno en 1934, mediante permuta con los herederos de Gandarias. El diplomático y coleccionista costarricense doctor Fernando Iglesias poseyó la pintura correspondiente a la Confesión general que J. Antonio Villacorta y sus seguidores denominaron La confesión, equivocando totalmente, con Fray Lázaro Lamadrid, la fecha y el punto donde ésta tuvo lugar, porque empeñados en la existencia de Fran-

22 Fernández, 1959 p. 123 , afitma habet visto de joven la setie de la vida de San Francisco completa en el claustro conventual de San Ftancisco en la Nueva Guatemala, diciendo que después de la exclaustración, en 1873, dichas pinturas debieron llevatse al coro y a la sacristía, de la iglesia franciscana, en donde estaban colocadas en pésimas condiciones para su conservación en 1897. Podemos añadir nosotros que allí permanecieron hasta los terremotos de 1917-18, cuando los destrozos en la aludida iglesia provocaton a su vez la destrucción de la mayor parte de dicha secuencia pictórica, sobreviviendo únicamente las que adquirió don Justo de Gandarias y otras que se quedaron en la sacristía, que según Castellanos fueron cuatro, pero de las que ahora quedan únicamente tres. 
cisco de Villalpando señalaban que esto había tenido que ser en la iglesia de San Francisco de Santiago de Guatemala, a raíz de los terremotos de 1717 , siendo que el único Villapando ni siquiera viajó a Guatemala. Desconocemos como esta pintura pasó a poder del Museo Nacional, pero cuando se inauguró la sala Villalpando del mismo, ya formaba parte de los once que ctualmente son del Museo Colonial en Antigua Guatemala. ${ }^{23}$

Ya hemos señalado que fueron "retocadas" estas pinturas por el señor Manuel Barillas Nisthal y la señorita Antonia Matos Aycinena lo hizo con el Bautizo de San Francisco, personas que hasta donde sabemos no eran desde luego especialistas en restauración de pinturas de caballete. Pero el colmo de la mala suerte fue que durante el régimen del general e ingeniero Miguel Idígoras Fuentes se le encargara la "restauración" de las mismas, por una suma entonces muy jugosa, a un pintor de nacionalidad española o mexicana, ambicioso, mediocre e irresponsable llamado José Mas, en contra de la opinión del Instituto de Antropología e Historia, quien pegó con materiales inadecuados las telas a pliegos de madera de capas, previamente a lo cual cortó las mismas sin molestarse en separarlas de sus bastidores, trabajo que finalmente se logró detener cuando ya el daño estaba hecho. ${ }^{21}$

Las otras tres pinturas de Villalpando, y no cuatro como han afirmado algunos autores, permanecieron en la sacristía de la iglesia de San Francisco, y luego en el Museo Fray Francisco Vázquez, siendo ellas La Cena eucarística de San Francisco de Asís, El Jubileo de la Porciúncula y El carro de San Francisco, que describiremos oportunamente, pero también se encontraban en no muy buen estado de conservación ${ }^{25}$

Tomando como base las descripciones hechas por De la Maza y don Rafael Arévalo Martínez, así como las fuentes biográficas tradicionales de San Francisco de Asís, como son Las florecillas de San Francisco, La vida de San Francisco de Asis, por Tomás de Celano; La leyenda de San

23 Poco antes de la inauguración de la "Sala Villalpando" del Museo Nacional en 1936, éste adquirió del Dr. Iglesias el lienzo denominado "Confesión general", que dicho coleccionista probablemente compró a los franciscanos o a Gandarias.

24 "Es lamentable que haya podido suceder algo así por ótdenes superiores", sin atender la opinión de la entidad técnica encargada de la custodia de dichas pinturas El estado en que fueron devueltos por el "pintor y restaurador" fue lamentable, particularmente por la mutilación sufrida en las orillas de las telas y la genial idea de pegar dicho soporte con engrudo a tablas de madera de capas.

${ }^{25}$ En la actualidad se encuentran en proceso de restauración por el Taller de Restauración de Bienes Muebles del Consejo Nacional para la Protección de la Antigua Guatemala y del Instituto de Antropología e Historia, La Muerte de San Francisco y el Tubileo de la Porciúncula, respectivamente. Pronto seguirán otras pinturas dicho proceso de restautación. 
Francisco de Asís por San Buenaventura, y la Leyenda de los tres companeros así como la de Facchinetti ${ }^{26}$ describiremos rápidamente las catorce pinturas:

\section{Bautizo de San Francisco $(3.22 \mathrm{~m}$. alto $\times 2.12 \mathrm{~m}$. ancho).}

Se trata de un tema que la iconografía franciscana ha idealizado y que Villalpando pintó colocando un nutrido grupo de personas que presencian el acto del bautismo rodeando la pila bautismal que se encuentra en el centro: sobre ella aparece el niño sostenido por uno de los padrinos, de los cuales el situado en el extremo izquierdo resulta ser, según de la Maza, un autorretrato del propio Villalpando. Frente a la pila bautismal se ve una bella jarra renacentista junto a la cual un pequeño perro observa incongruentemente la escena en la que se ven flores en el piso, y el obispo procede a bautizar a San Francisco: inmediatamente detrás de la pila, que está labrada en piedra fina, se ve un ángel cuyas alas irrumpen extrañamente en la escena. En el lado izquierdo se ven en primer plano, una columna salomónica que nos está indicando la presencia del barroco. En el fondo hay una escenografía arquitectónica muy bella que, según el mismo de la Maza, bien pudiera ser el interior de la iglesia de San Agustín, recién estrenada en 1691 y que tradicionalmente se ha dicho ser obra del propio Villalpando. No cabe duda que es una de las mejores pinturas de la serie, tanto en su composición como en el colorido y cuidado puesto en todo el conjunto. Está firmada.

\section{San Francisco se despoja de sus vestiduras}

$(2.35 \mathrm{~m}$. alto $\times 2.73 \mathrm{~m}$. ancho).

De acuerdo con la tradición San Francisco se ve hincado ante el Obispo, quien trata de cubrir la desnudez de San Francisco, que viste únicamente los enormes calzones característicos de su época, con su capá, el obispo trata de cubrirlo viéndose flanqueado por dos pajes desproporcionados en su altura junto al dignatario. El padre de San Francisco se ve acompañado de seis personas, todos vestidos en la moda del siglo XVII, al igual que lo son las ropas de San Francisco que se ven amontonadas, incluyendo una lujosa espada, en primer plano en el centro. En el fondo

${ }^{26}$ Legísima, Fray Juan R de Gómez Cañedo, Fray Lino (editores), San Francisco de Asis, Escritos completos y biografias primitivas Madrid, Biblioteca de Autores Cristianos, 1956 y Facchinetti, O.F.M. Fray Victorio, San Francisco de Asis en la Historia, en la leyenda, en el arte 2 Vols. Biblioteca Franciscana, Barcelona-Madrid, 1925. 
aparece el interior de una iglesia, extrañamente visible desde el palacio obispal en donde supuestamente tenía lugar la escena anteriormente descrita. Es una de las pinturas que se encuentra en peor estado de conservación, por lo que es difícil opinar sobre su calidad, requiriéndose de una pronta restauración. No está firmada.

\section{San Francisco y la tempestad. ( $3.34 \mathrm{~m}$. alto $\times 2.26 \mathrm{~m}$. ancho).,}

San Francisco que viajaba de polizón cuando trató de ir a convertir al sultán de Turquía, se ve en compañía de otros frailes y de varios marinos que tratan de arriar la vela de la pequeña embarcación que parece literalmente una nuez o una concha, mientras uno de ellos controla la barra del timón. Resulta complicado afirmar si la influencia en Villalpando proviene de un grabado o de la propia pintura de Echave Ibía pero la composición resulta interesante por lo ondulante, según de la Maza. Está firmada.

\section{El Capitulo de las esteras $(2.26 \mathrm{~m}$. alto $\times 2.64 \mathrm{~m}$. ancho $)$.}

San Francisco había convocado a Capítulo General concurriendo más de cinco mil frailes franciscanos, si bien también asiste Santo Domingo de Guzmán y varios de su orden. En el fondo se ven diversas tiendas de campaña hechas de esteras o petates así como de un árbol de grueso tronco que se ve en el centro de la pintura en discutible solución compositiva. En primer plano, precisamente delante del aludido árbol están San Francisco y otras personas y a sus lados varios personajes entre los que se observan un obispo y caballeros que le llevan vituallas. Al lado izquierdo se ve una mesa servida en la cual varios franciscanos se preparan a comer. La pintura la podemos conceptuar de regular calidad. El autor no la firmó, aunque hay un fragmento faltante del lienzo donde pudo estar ésta.

\section{Conversión de dos ladrones ( $2.27 \mathrm{~m}$. alto $\times 2.94 \mathrm{~m}$. ancho).}

Varios ladrones fueron a pedir comida a un convento franciscano siendo despedidos de mala manera: enterado San Francisco envió al fraile responsable de ello para que les alcanzara, pidiera perdón y les diera de comer, actos que hicieron que los ladrones se convirtieran posteriormente en frailes, según Las florecillas de San Francisco. En la pintura se ve a los dos ladrones arrodillados ante San Francisco quien tiene a su lado a fray Ángel; los caballos de los ladrones tienen una curiosa mirada terrible, como la de los que tiran del carro en que va San Francisco, en la pintura 
número siete de esta serie. La escala de las figuras y la perspectiva de las cabalgaduras resulta algo defectuosa. En el fondo se ve un paisaje con una iglesia que más se nos antoja flamenca que novohispana. La pintura nos parece de mediana calidad y va firmada del pintor.

\section{Confesión general $(2.31 \mathrm{~m}$. alto $\times 2.94 \mathrm{~m}$. ancho) .}

Según Celano, hombres, mujeres, clérigos y religiosos acudian en gran muchedumbre para ser testigos de las maravillas que obraba San Francisco, creando una euforia religiosa que hacía que las personas se confesaran en gran número. Esta escena fue confundida por los seguidores de Francisco de Villalpando, como la "Confesión General", adscribiéndola equivocadamente a los terremotos de San Miguel de 1717 y Fray Lázaro Lamadrid a un milagro de la Virgen del Coro en la iglesia franciscana, en 1641 , es decir que ambos están equivocados toda vez que Villalpando nunca estuvo en Guatemala y debió copiar el modelo de Echave Ibía. ${ }^{27}$ La escena muestra tres focos de atención que están representados, primero por un grupo de personajes que se encuentran al lado izquierdo confesándose ante un fraile franciscano; otro grupo está a la derecha y entre ellos sobresale un caballero ricamente vestido con el traje de la época de Villalpando y en la parte central y superior, como tercero, la Virgen y el Niño, siendo ésta coronada por dos ángeles, que forman parte con otros, de un rompimiento de gloria. En primer plano y en el centro dos niños platican absortos y en el fondo, a ambos lados, se ven escenas interiores de un templo, notándose en el lado derecho al Espíritu y un retablo barroco. La pintura está firmada y es de las más impresionantes del conjunto.

\section{Carro de fuego de San Francisco $(2.22 \mathrm{~m}$. alto $\times 2.95 \mathrm{~m}$. ancho).}

Relata Celano que en cierta oportunidad San Francisco se separó corporalmente y hacia media noche varios franciscanos uitos en reposo y otros en oración vieron entrar por la puerta de la vivienda donde se encontraban "... Un carro en llamas, sobre el que se eleva un globo que,

27 Resulta imposible de saberse hasta que punto fue fiel Villalpando en la copia de las pinturas de Echave Ibía, mientras no se conozcan éstas. Nuestta opinión es que debió ceñirse como lo dice el contrato, bastante a sus originales. Para la serie franciscana de Luis Berrueco, debe consultarse: Vargas Lugo, Elisa y Díaz, Marco, "Historia, leyenda y tradición, en una setie franciscana" en Anales del Instituto de Investigaciones Estéticas. Vol XII, no 44 (1975 México), Universidad Nacional Autónoma de México, pp. $59-82$ 
resplandeciente como el sol, convertía la noche en clarísimo día ..." Dicha luz no sólo alumbraba los cuerpos sino que permitía ver la conciencia interior de cada uno.

Villalpando pintó un pequeño carro de fuego donde va San Francisco sentado; el respaldo del vehículo tiene forma de concha y el mismo va tirado por cuatro corceles blancos, dos de los cuales ven al espectador desafiantes mientras los dos primeros ya han cruzado y se alejan. En primer plano siete frailes franciscanos se ven sorprendidos ante la aparición abandonando unos la lectura y otros simplemente mostrando su asombro. Hay una separación entre los frailes que se encuentran en primer plano y el carro que cubre toda la parte alta de la pintura y que está marcada por una nube sólida sobre la que caminan carro y corceles. El cuadro está firmado y es de mediana calidad.

\section{Jubileo de la Porciúncula ( $2.34 \mathrm{~m}$. alto $\times 2.93 \mathrm{~m}$. ancho).}

San Francisco obtuvo que quienes entraran con arrepentimiento en esta pequeña iglesia conseguirían indulgencia plenaria como quienes hubieran ido a las cruzadas contra los infieles.

Numerosas alusiones hacen los textos tradicionales franciscanos a la relación entre el santo y diversos hechos milagrosos acaecido en este templo cercano a Asís, que en este caso se refiere a que le fue otorgada este especial privilegio a esta pequeña iglesia pero tan querida por San Francisco. En la obra de Villalpando aparece San Francisco hincado ante un altar recubierto de brocado morado, en una posición muy similar a una pintura de Echave Orio referida a la estigmatización. Está rodeado de cuatro arcángeles, que empequeñecen al santo, todo lo cual integra el primer plano de la pintura. En el ángulo superior se ven ángeles músicos (uno toca el arpa y el otro el violoncelo) y abajo de esta escena se ve otra pequeña con la Natividad. En el ángulo superior izquierdo, Jesús y la Virgen María observan a San Francisco y en la parte central superior otros ángeles llevan flores y quizás racimos de uva, apareciendo otra vez flores esparcidas en el suelo. Está firmada y al limpiarse han aparecido agradables colores.

\section{Regreso de San Francisco del Monte Alverna}

( $2.28 \mathrm{~m}$. alto $\times 2.74 \mathrm{~m}$. ancho).

Afirman las fuentes franciscanas que al volver el santo del Monte Alverna, acudían a verlo multitud de personas y muchas de ellas llevaban ramos de olivo en las manos. La escena idealizada por Villalpando tratan- 
do de recordar a Cristo el Domingo de Ramos, muestra una ciudad a la que entra San Francisco cabalgando un borrico y bendiciendo colocándose telas en el suelo para que éste pasara sobre ellas. En las casas de altos se ven alfombras y reposteros en los balcones a la manera que se hacía en Hispanoamérica cuando habían ceremonias públicas. Una procesión sale de una iglesia para recibir al santo. El lienzo está firmado y es uno de los mejores de la secuencia franciscana. No está firmada.

\section{Muerte de San Francisco $(2.27 \mathrm{~m}$. alto $\times 2.61 \mathrm{~m}$. ancho) .}

Sintiéndose morir hizo San Francisco que le colocasen desnudo sobre la tierra, según Celano, para luchar con el Enemigo: cubrió con la mano izquierda la llaga de su costado, luego se puso el hábito y expiró. Según Las florecillas de San Franciscano lo acompañaron varios de sus principales frailes y la señora Jacoba de Siete Solios, quien en otras oportunidades lo había cuidado. El artista puso a San Francisco oblicuamente, vestido únicamente con sus calzones, rodeado de los cinco frailes y la mujer; frente a él un bello recipiente de plata: toda esta escena terrenal se ve separada de la parte superior por un rompimiento de gloria en el que se ven en el lado izquierdo, frailes franciscanos que son liberados por la muerte del santo, inmediatamente después de los cuatro evangelistas, luego la Virgen y Jesús y en el centro al Santo Padre. Hacia la derecha se ve a San Juan Bautista y diversos santos fundadores de órdenes religiosas. La pintura está firmada y es de mediana calidad.

\section{Cena eucarística de San Francisco $(2.31 \mathrm{~m}$. alto $\times 2.68 \mathrm{~m}$. ancho).}

Se trata de una escena alegórica pues no la hemos podido localizar en ninguna de las fuentes franciscanas, lo cual ha sido relativamente frecuente en la iconografía tan rica de este santo. Jesús y San Francisco se ven en primer plano y en el centro y en medio de ellos una pequeña mesa siendo rodeados por una bella escena de floresta muy renacentista que recuerda la "Vegetación del Paraíso" que se encuentra en la capilla del ochavo de la catedral de Puebla, serie realizada en 1689 y que mide apenas $88 \mathrm{~cm}$., es decir que son casi miniaturas de clara influencia flamenca. Numerosos angelitos presencian la escena volando alrededor de las dos figuras principales en una composición circular, llevando flores muchas de las cuales se ven esparcidas en el suelo como rindiendo homenaje a la escena sagrada, a la manera originada en Andalucía, según De la Maza. La presencia de los pequeños ángeles y de la vegetación convierten el 
DOI: http://dx.doi.org/10.22201/iie.18703062e.1986.57.1327

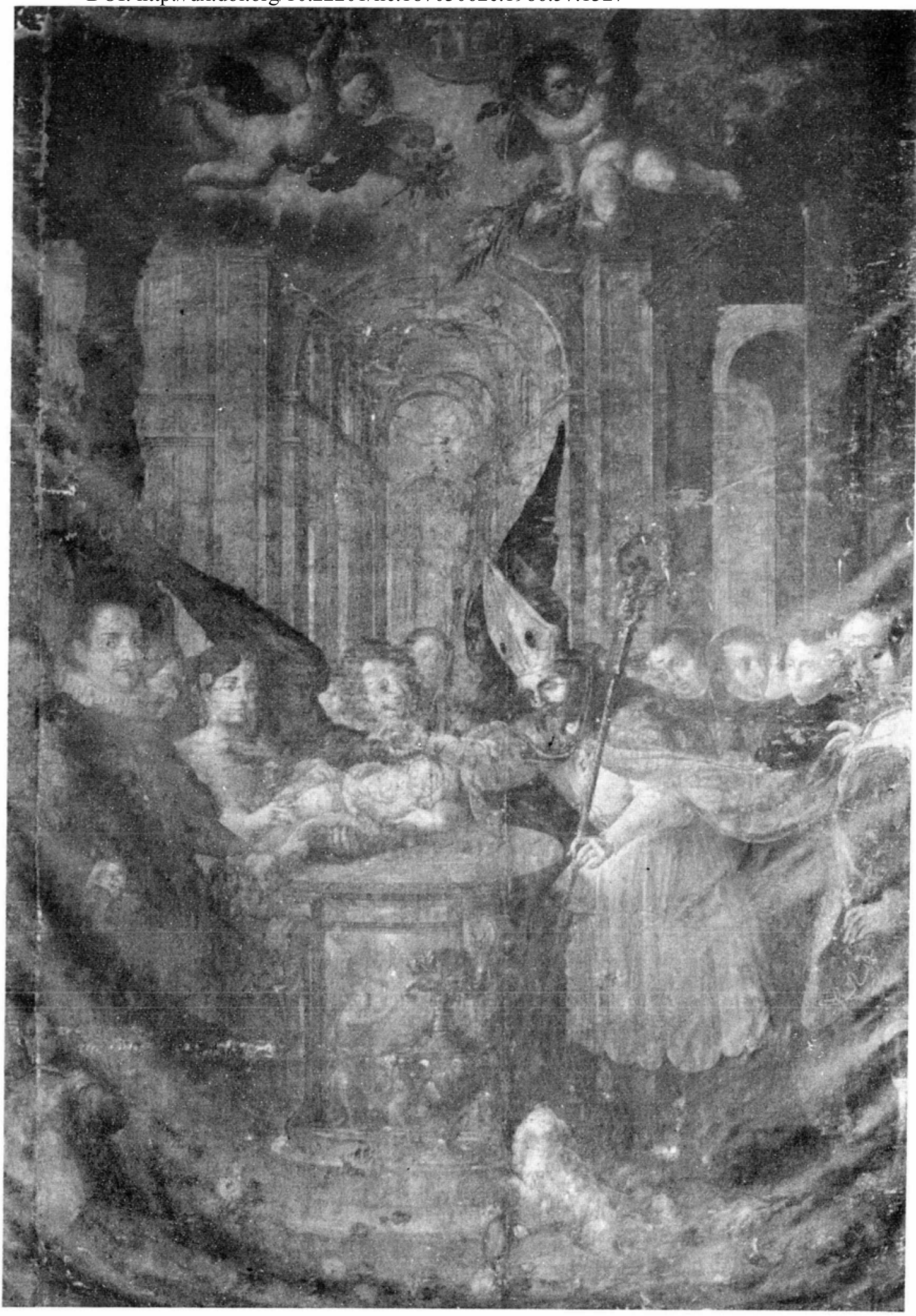

Figura 1. Cristóbal de Villalpando. Bautizo de San Francisco. 
DOI: http://dx.doi.org/10.22201/iie.18703062e.1986.57.1327

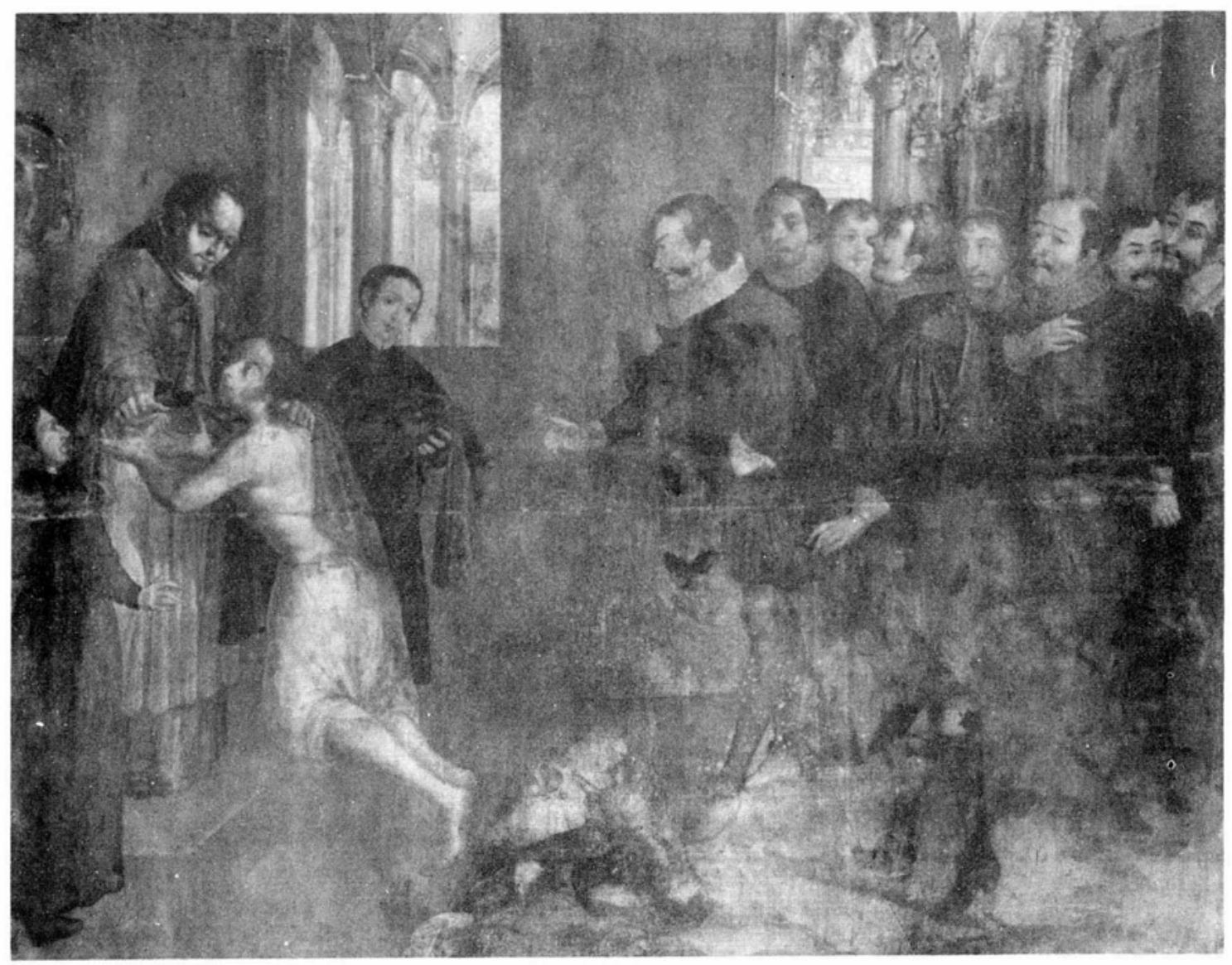

Figura 2. Cristóbal de Villalpando. San Francisco se despoja de sus vestiduras. 


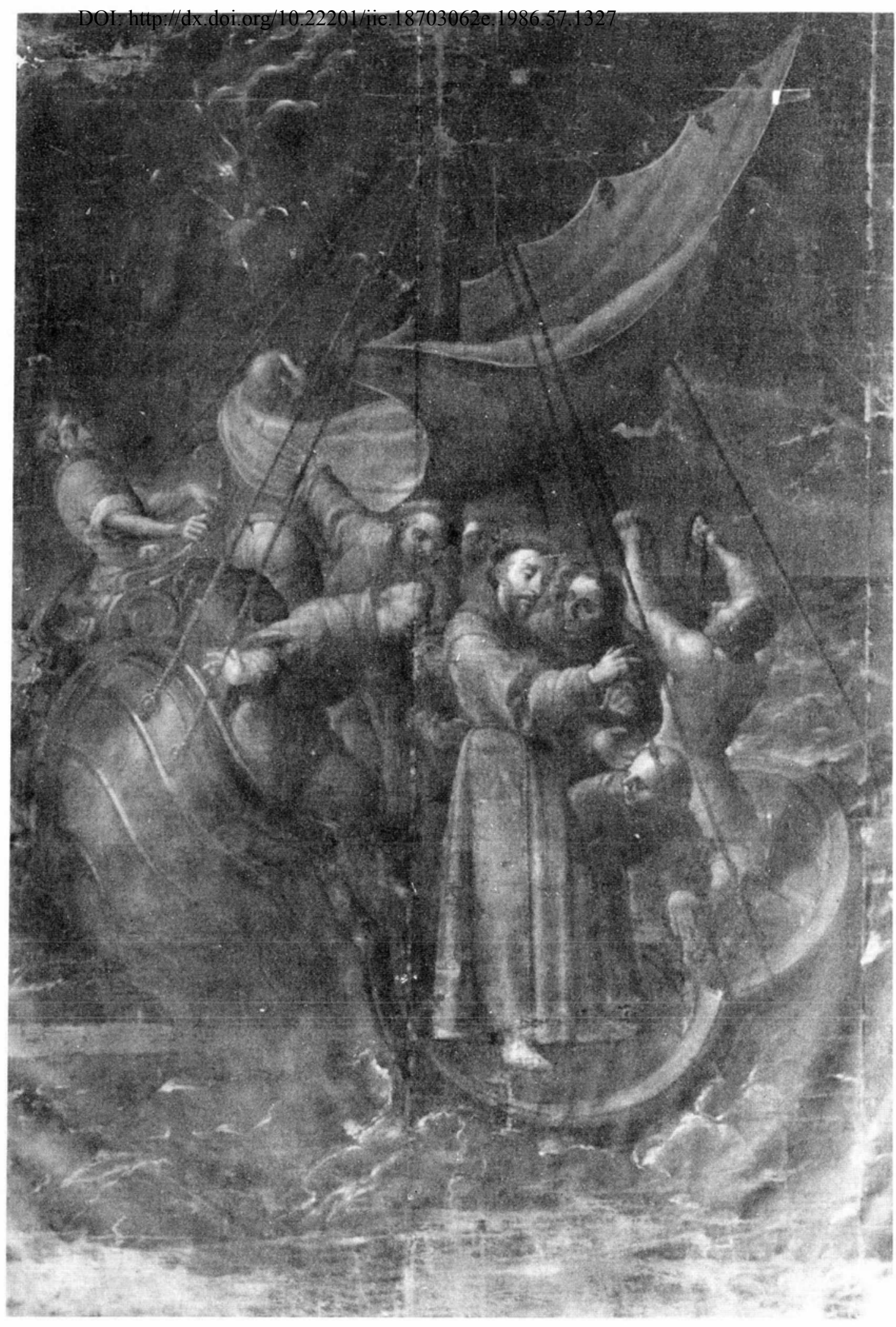

Figura 3. Cristóbal de Villalpando. San Francisco y la Tempestad. 
DOI: http://dx.doi.org/10.22201/iie.18703062e.1986.57.1327

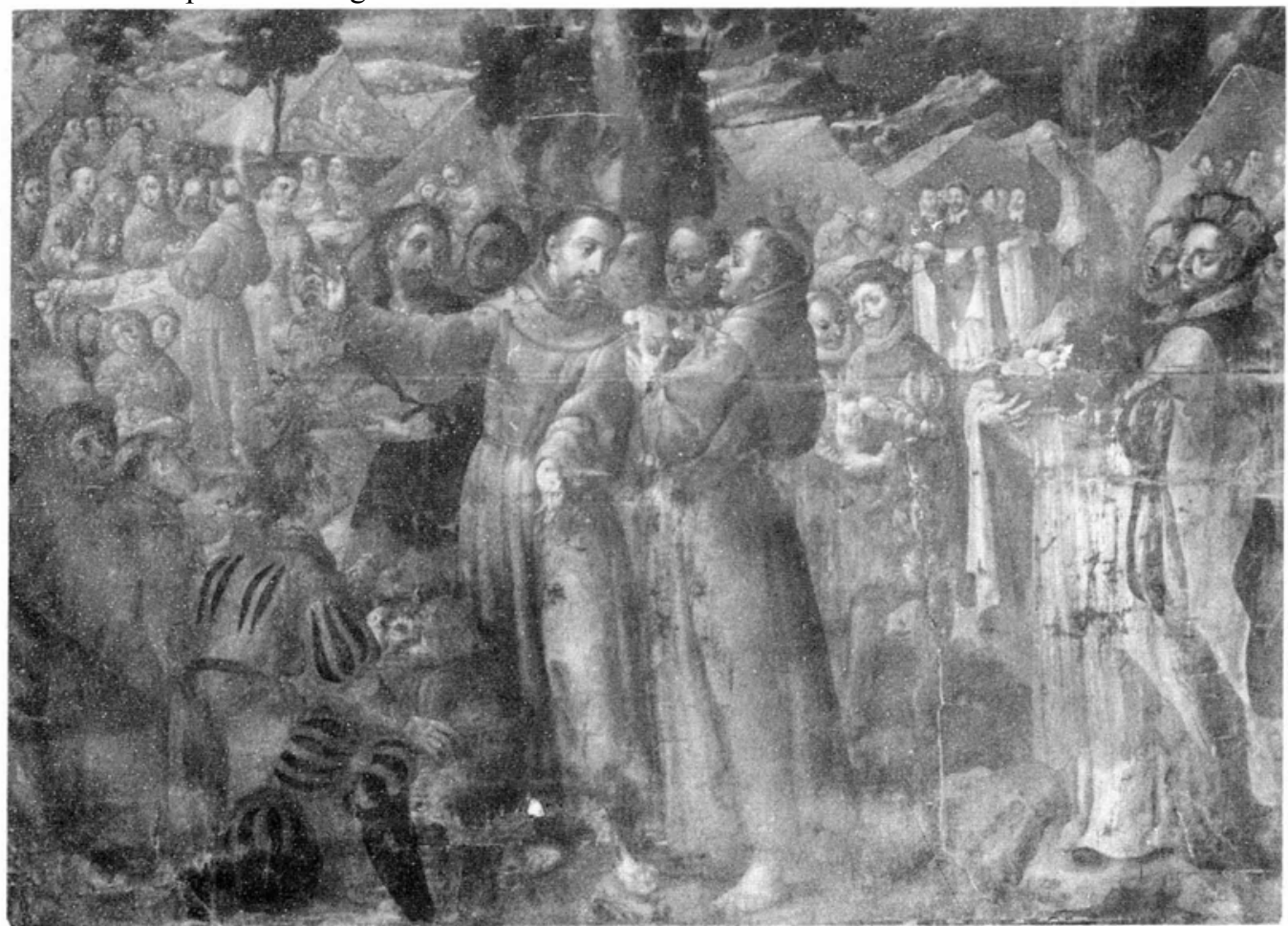

Figura 4. Cristóbal de Villalpando. El capítulo de las esteras.

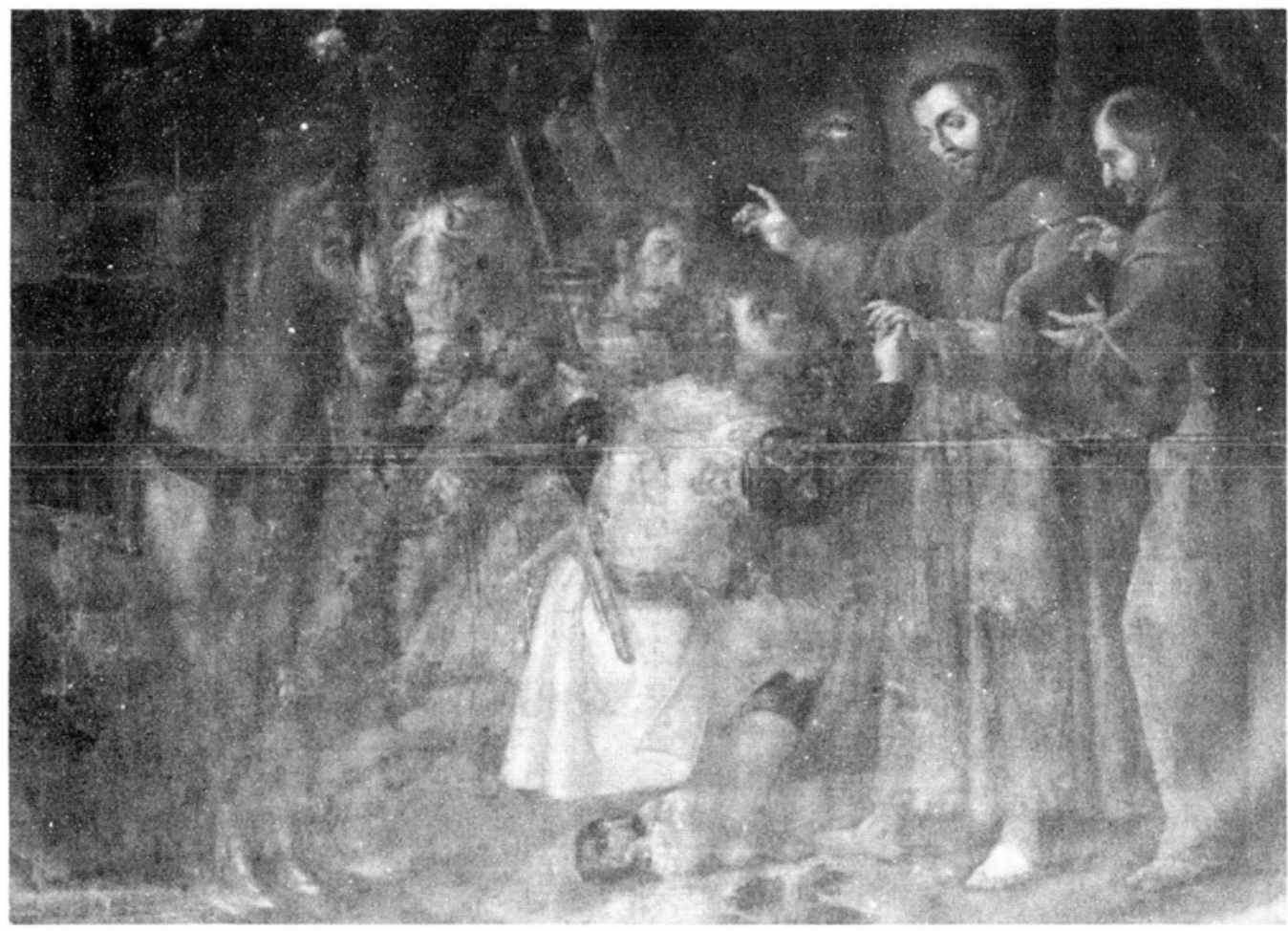

Figura 5. Cristóbal de Villalpando. Conversión de dos mazones. 
DOI: http://dx.doi.org/10.22201/iie.18703062e.1986.57.1327

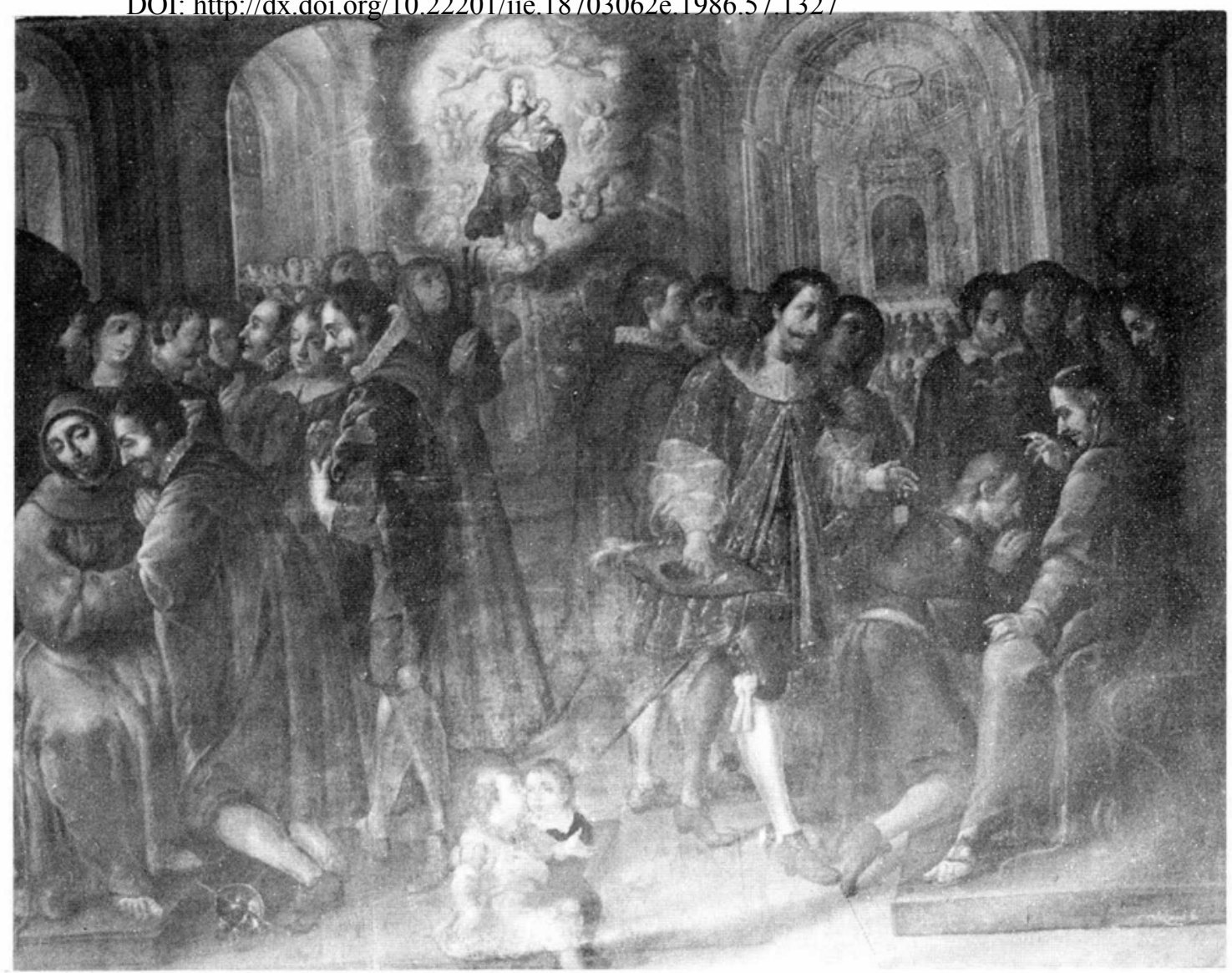

Figura 6. Cristóbal de Villalpando. Confesión general. 
DOI: http://dx.doi.org/10.22201/iie.18703062e.1986.57.1327

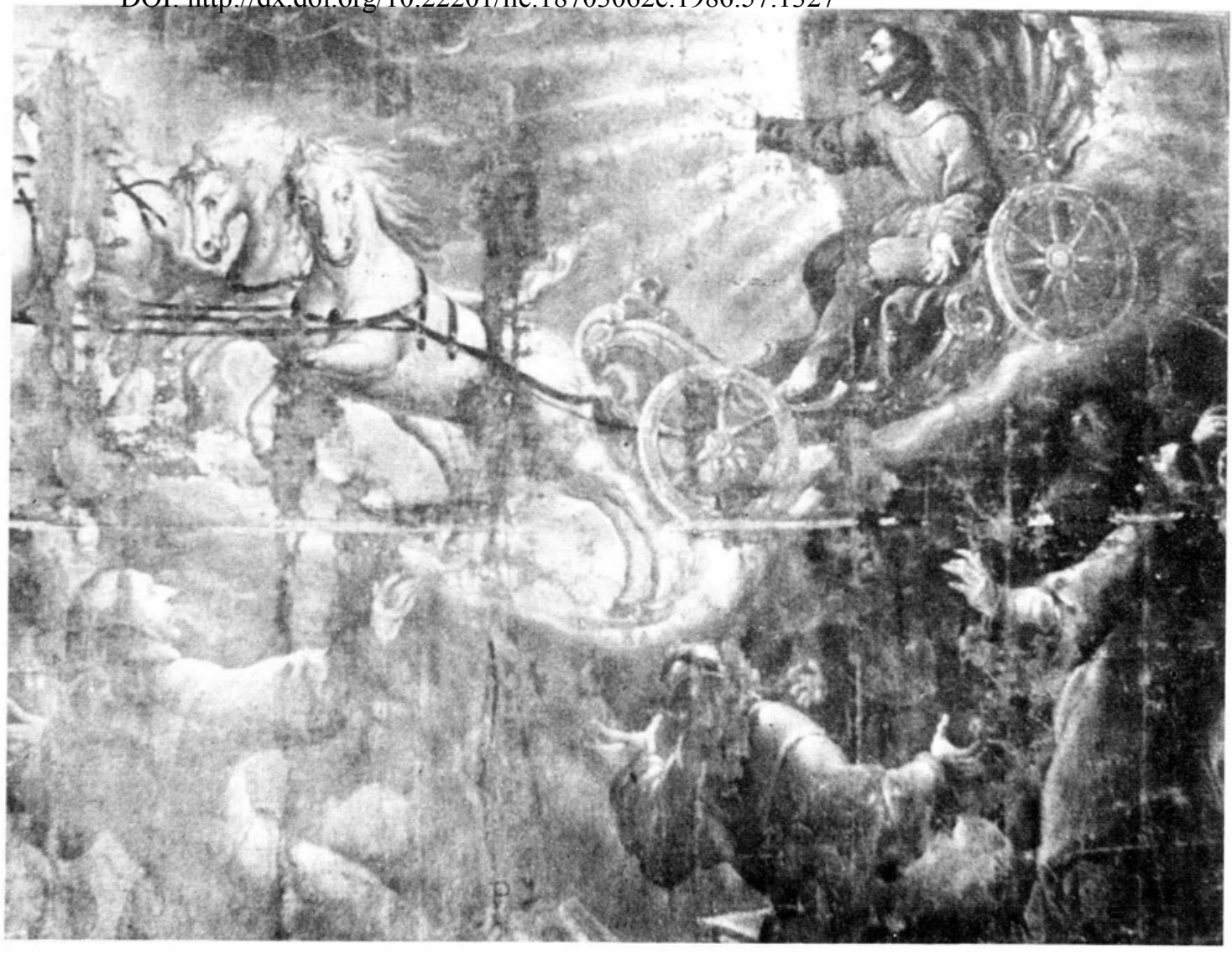

Figura 7. Cristóbal de Villalpando. Carro de fuego de San Francisco. 
DOI: http://dx.doi.org/10.22201/iie.18703062e.1986.57.1327

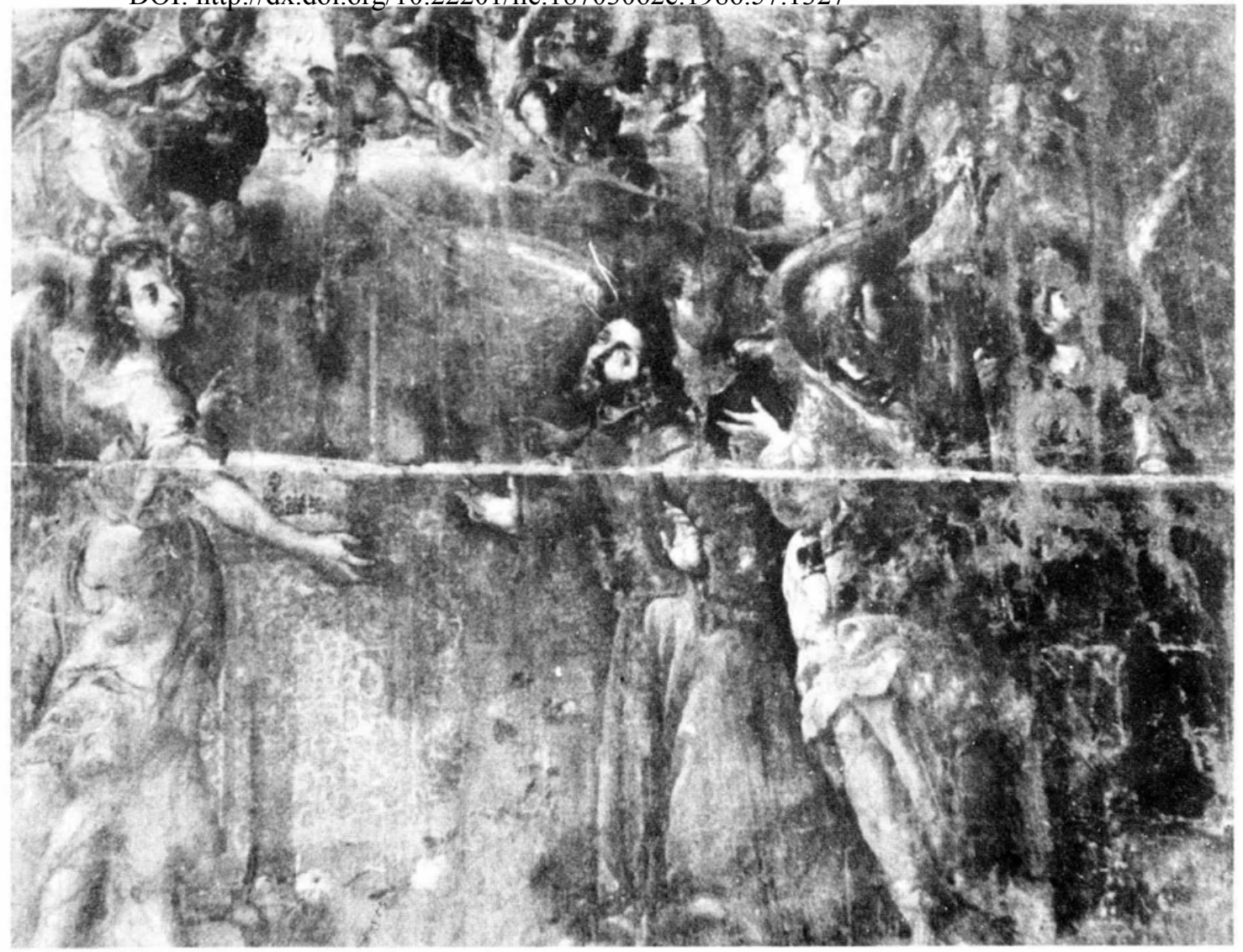

Figura 8. Cristóbal de Villalpando. Jubileo de la Porciúncula. 


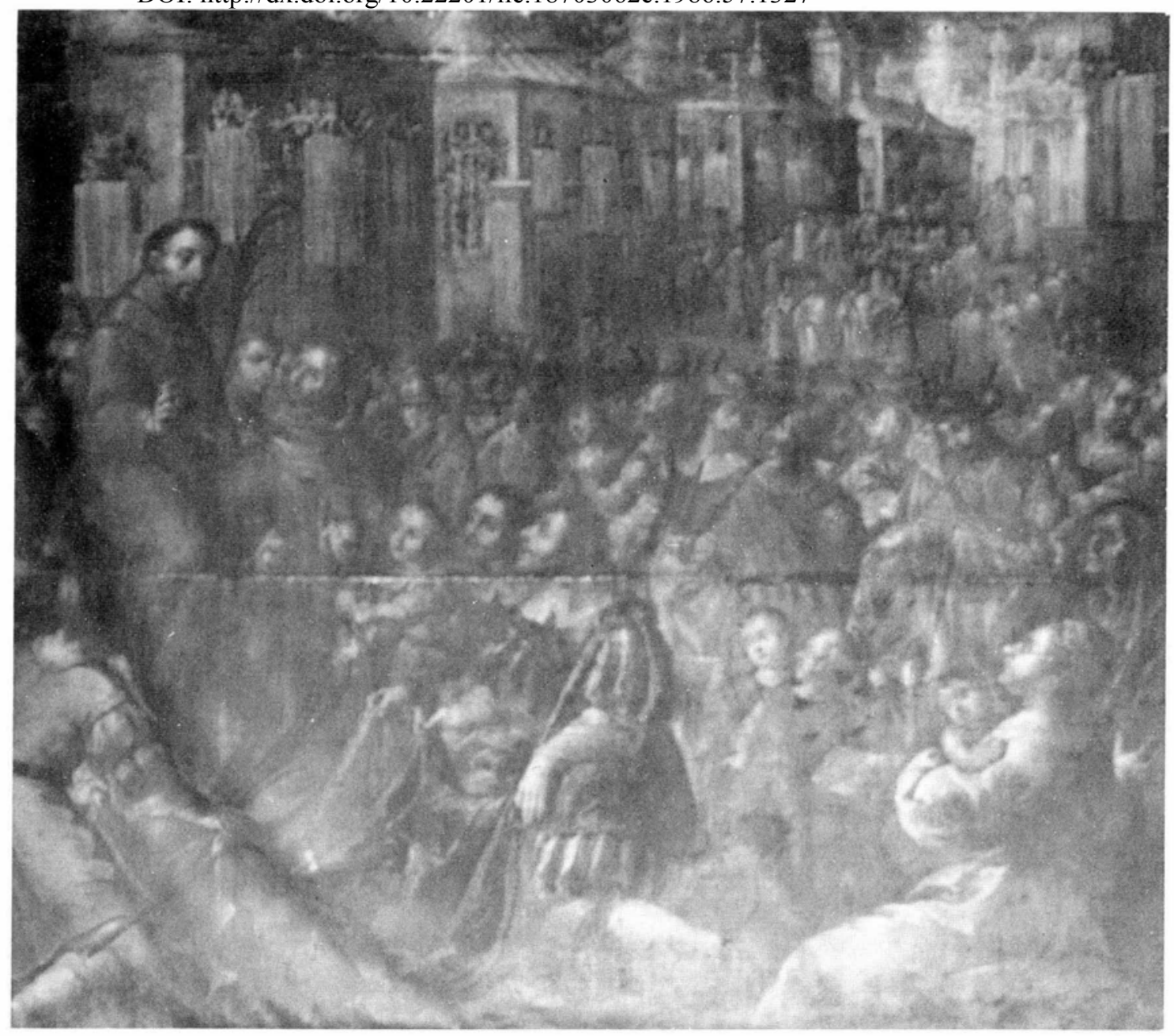

Figura 9. Cristóbal de Villalpando. Regreso de San Francisco del Monte Alverna. 
DOI: http://dx.doi.org/10.22201/iie.18703062e.1986.57.1327

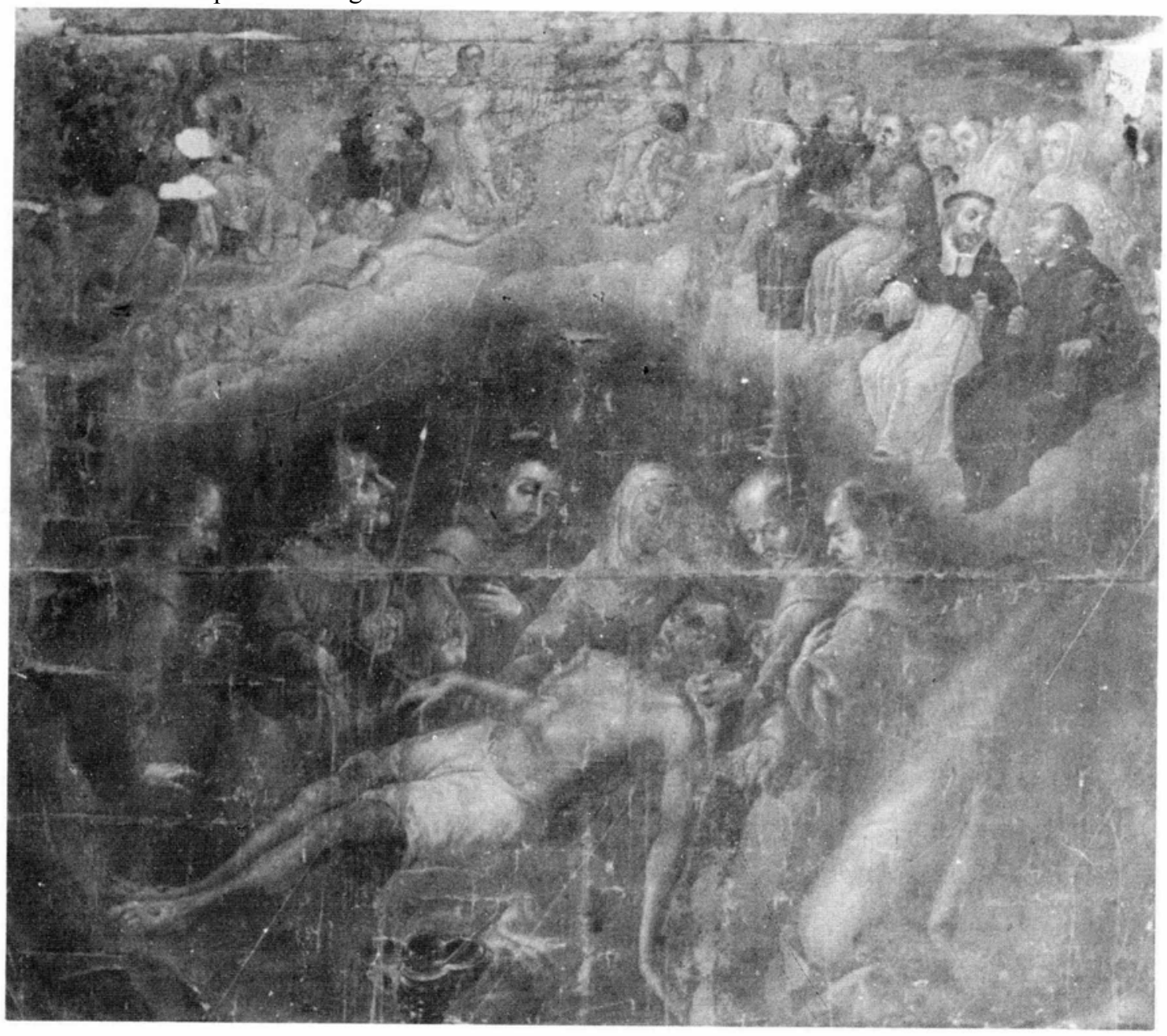

Figura 10. Cristóbal de Villalpando. Muerte de San Francisco. 
DOI: http://dx.doi.org/10.22201/iie.18703062e.1986.57.1327

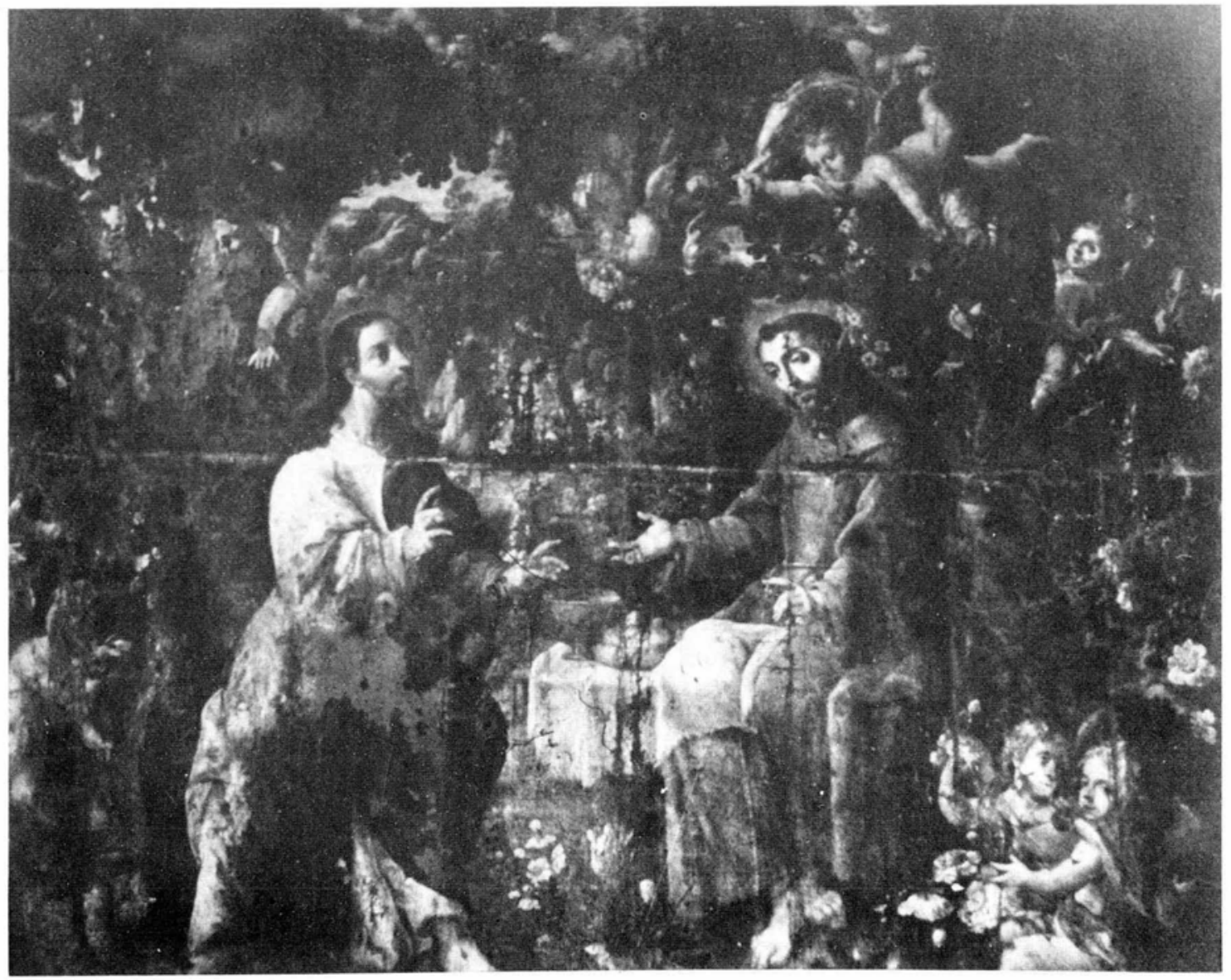

Figura 11. Cristóbal de Villalpando. Cena eucarística de San Francisco. 
DOI: http://dx.doi.org/10.22201/iie.18703062e.1986.57.1327

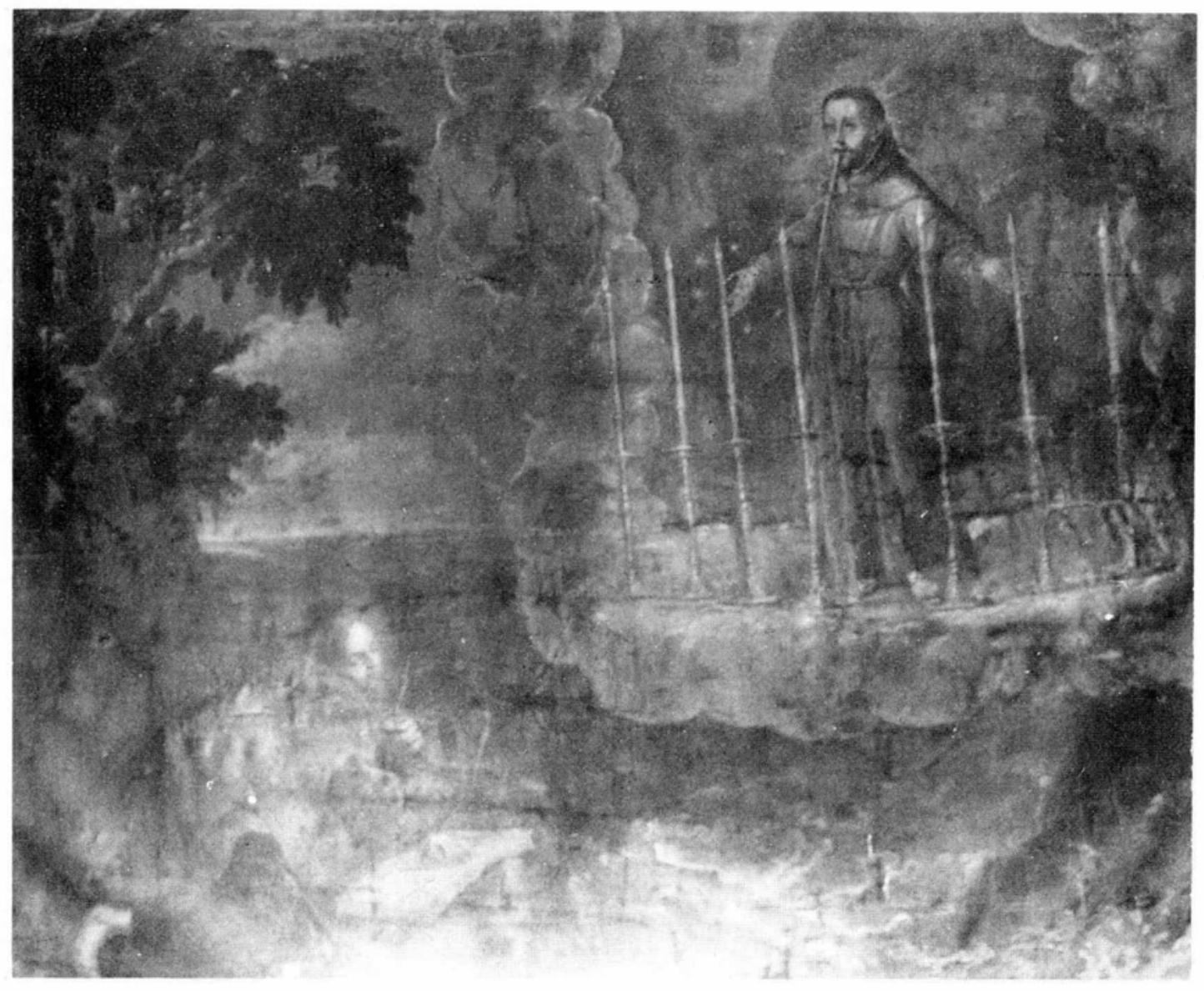

Figura 12. Cristóbal de Villalpando. San Francisco y el Apocalipsis. (A). 
DOI: http://dx.doi.org/10.22201/iie.18703062e.1986.57.1327

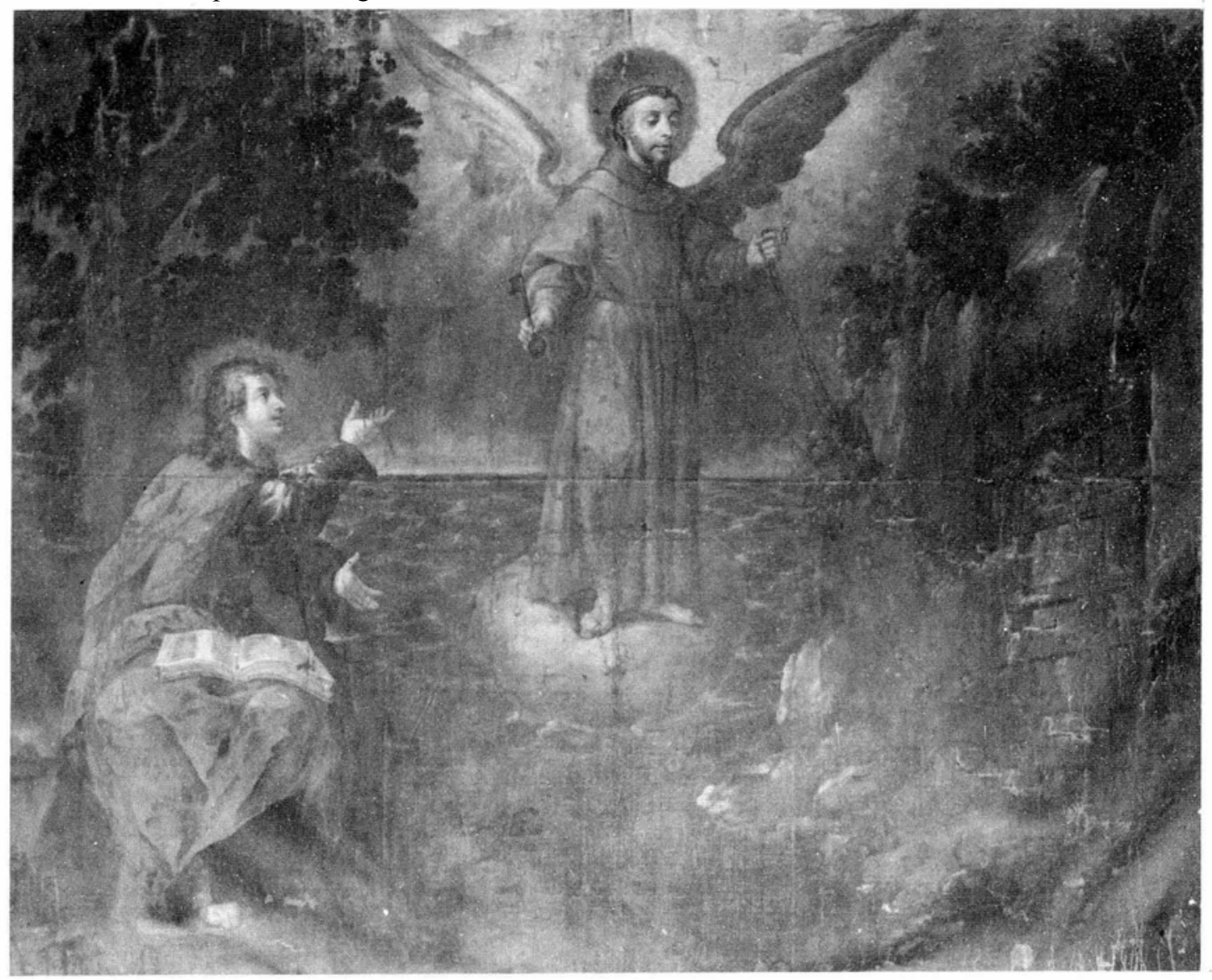

Figura 13. Cristóbal de Villalpando. San Francisco y el Apocalipsis. (B). 
DOI: http://dx.doi.org/10.22201/iie.18703062e.1986.57.1327

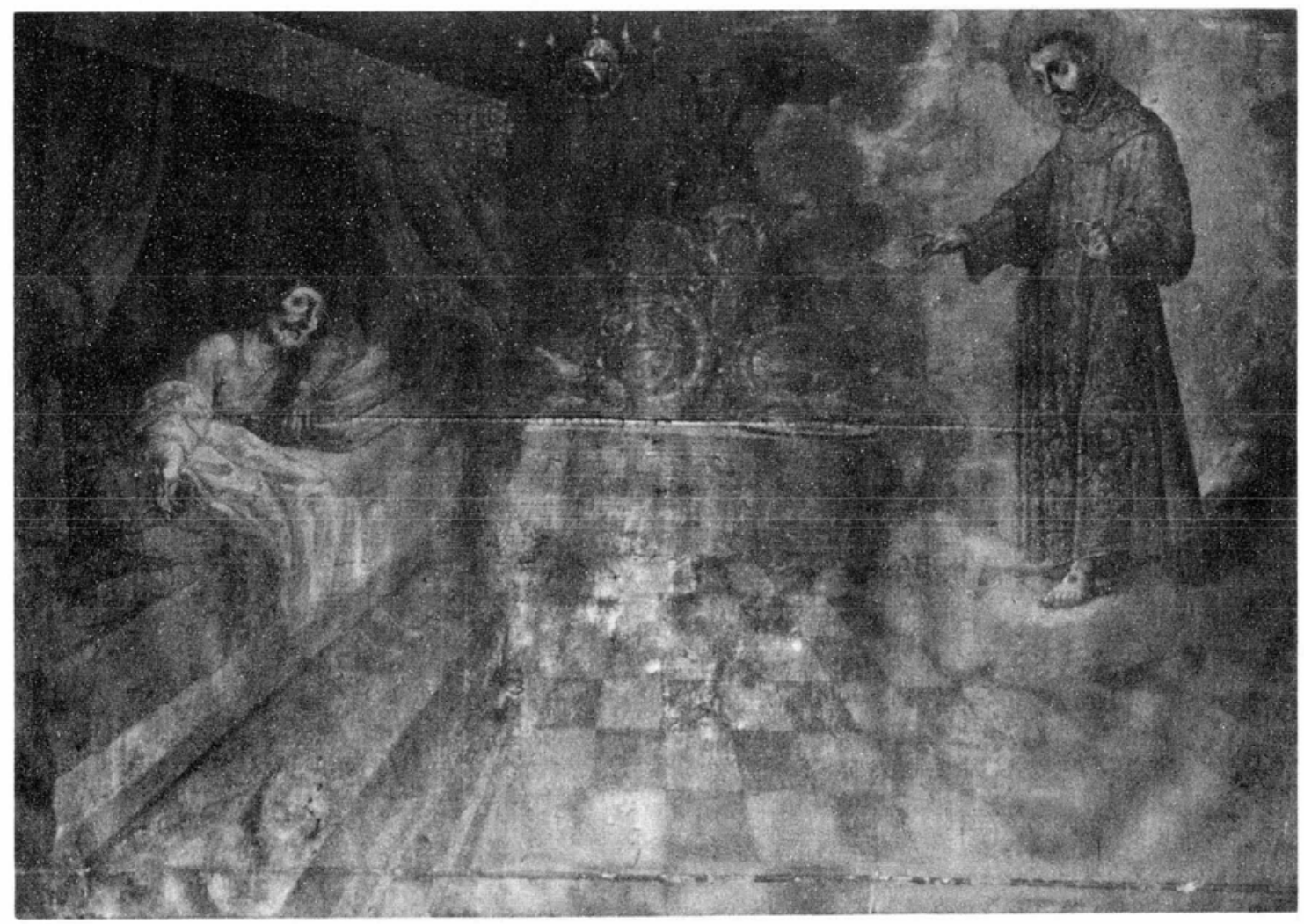

Figura 14. Cristóbal de Villalpando. El sueño del Papa Gregorio IX. 


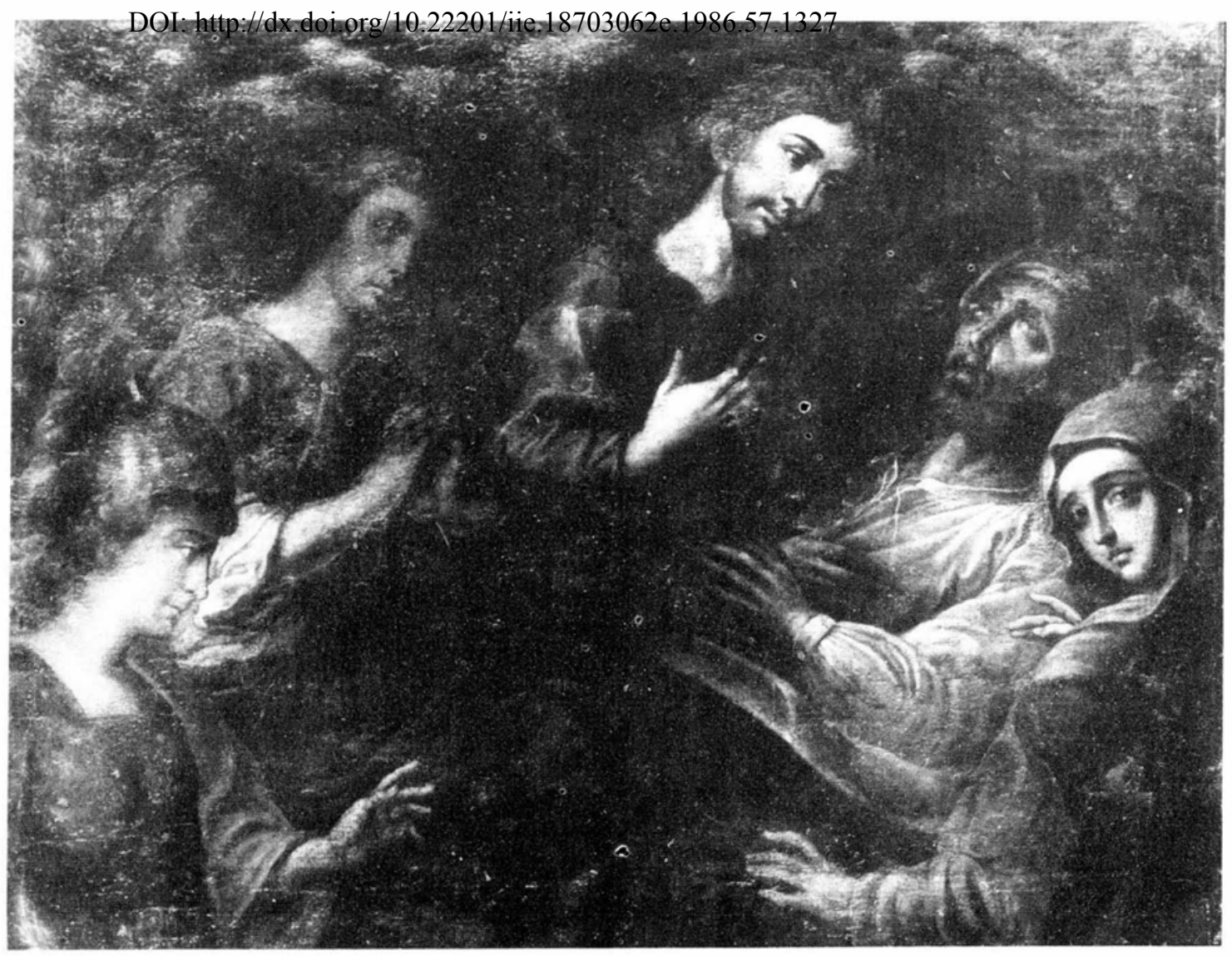

Figura 15. Cristóbal de Villalpando. La muerte de San José. Detalle. 


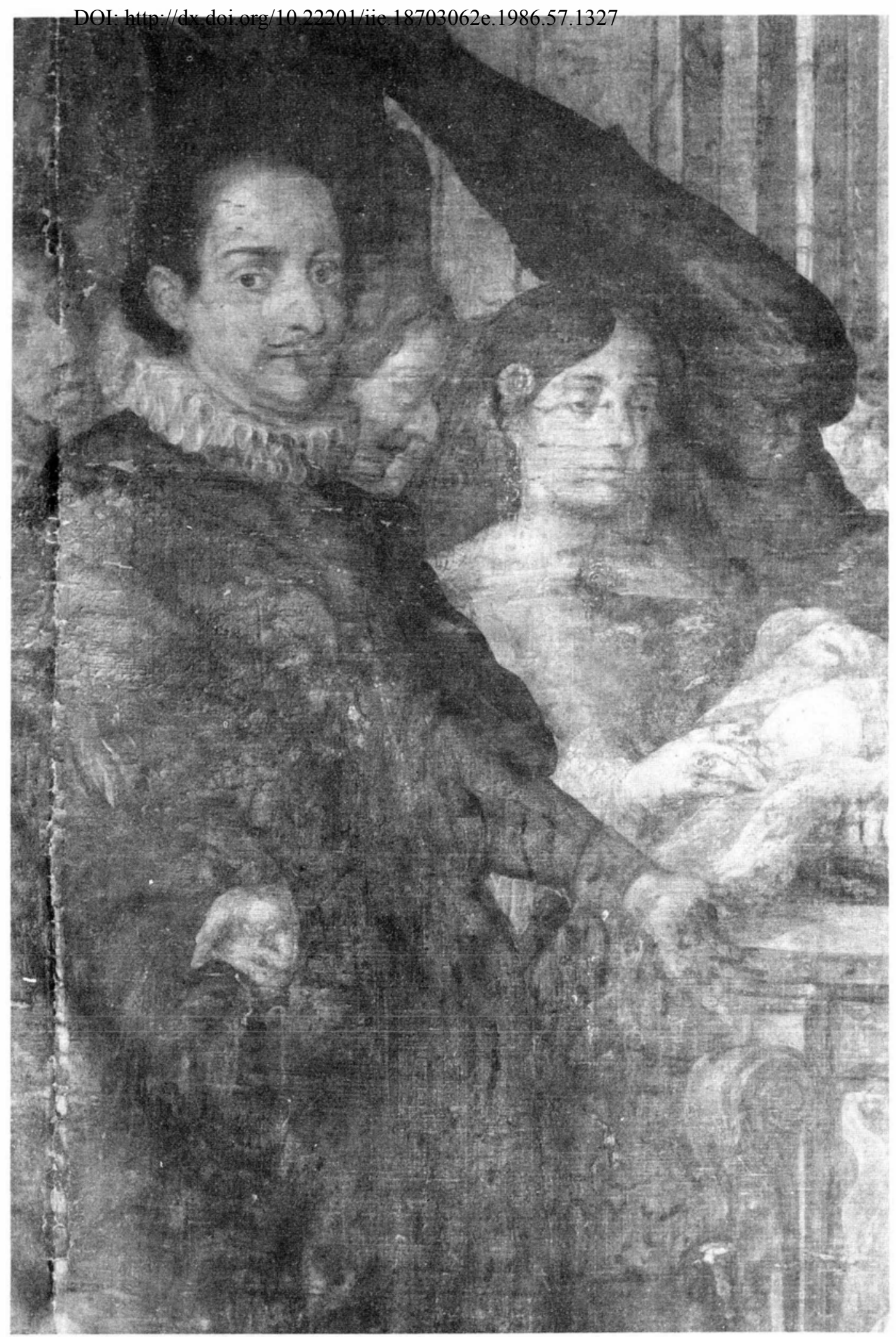

Figura 16. Cristóbal de Villalpando. Bautizo de San Francisco. Detalle. 


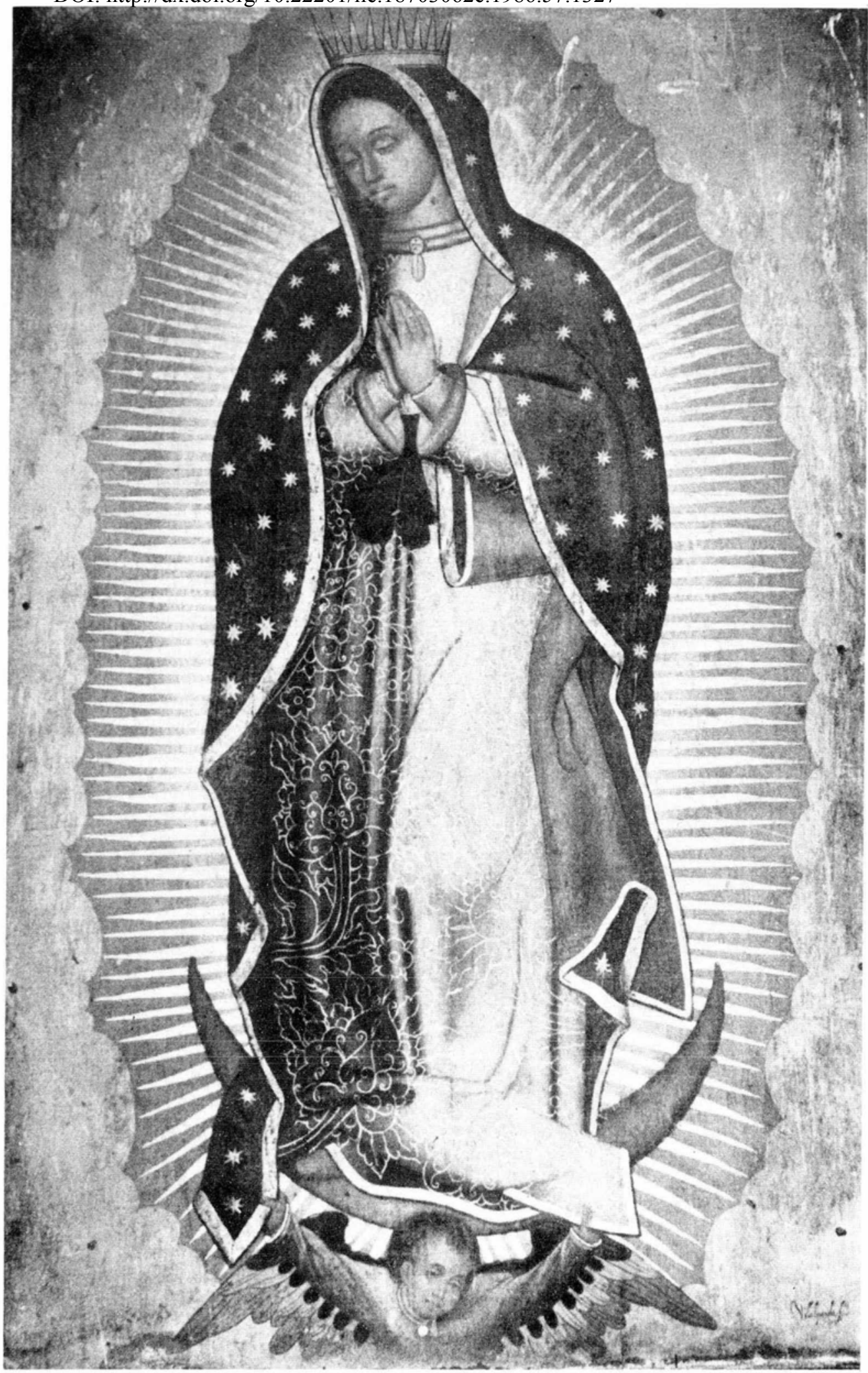

Figura 17. Cristóbal de Villalpando. Virgen de Guadalupe. 
tema central en secundario dada la prolijidad y belleza de la escena. El cuadro va firmando y es uno de los más hermosos de la serie, según nuestro criterio.

\section{San Francisco y el Apocalípsis. ${ }^{a}(2.27 \mathrm{~m}$. alto $\times 2.65 \mathrm{~m}$. ancho $)$.}

En esta escena de carácter alegórico, San Francisco aparece al lado derecho sobre una nube de textura poco ligera rodeado de siete candelabros de oro, en su boca se ve una espada de doble filo y en su diestra siete estrellas. En toda la parte inferior de la pintura se ven unas olas y en el ángulo inferior izquierdo se ve el apóstol San Juan que de rodillas sobre un libro señala con su diestra el texto en que se mencionaba la presencia de un hijo de hombre quien aparecería vestido con su túnica talar muy adornada con oro, lo que, sin embargo, no sucede con San Francisco. La composición es bastante deficiente, siendo una de las pinturas menos buenas de la serie. No está firmada.

\section{San Francisco y el Apocalipsis. ${ }^{\mathrm{b}}$ ( $2.27 \mathrm{~m}$. alto $\times 2.65 \mathrm{~m}$. ancho).}

En esta otra escena del apocalipsis, también alegórica, vuelve a aparecer San Francisco en lugar del ángel que descendió del cielo con la llave del abismo y con una cadena aprisionó al dragón o demonio por mil años. E1 pintor puso a San Juan muy joven, que señala a San Francisco, quien con alas va sobre una pequeña nube y lleva la llave y con una cadena que va unida a una puerta de hierro forjado que cierra la boca de una caverna, en la cual se ve un pequeño demonio que no inspira terror sino casi lástima. La composición y el color son bastante medianos; lleva la firma de Villalpando.

\section{El sueño del Papa Gregorio IX (2.32 m. de alto $\times 3.36 \mathrm{~m}$. ancho).}

Según San Buenaventura dudaba el Papa en inscribir a San Francisco en el libro de los santos, especialmente respecto a la veracidad de su llaga en el costado, por lo que se le apareció San Francisco mostrándole la herida y pidiéndoles una copa para depositar en ella sangre de la misma. En la pintura se observa una cama con escabel cubierto por una alfombra y con su dosel, todo muy a la manera del siglo XVII. El Papa duerme en una incomodísima posición sobre tres cojines con el brazo doblado, ocupando todo el lado izquierdo de la pintura. En el lado derecho del santo se le ve entre un rompimiento de gloria y vestido con rico hábito de bro- 
cado que recuerda la manera como se representaban dichos hábitos en la pintura y sobre todo en la escultura estofada de la época: de su herida sale un pequeño surtidor de sangre que cae en un recipiente de plata que se encuentra en una especie de mesa con gradas en donde de manera incongruente pero muy bellamente pintada, se ve una verdadera exhibición de orfebrería colonial entre las que sobresalen bandejas, platones, jarras, y ánforas de diversas formas. La pintura es mediana en su composición y en su colorido, salvándola el detalle de la orfebrería que podría ser por sí solo un cuadro. Está firmada por el artista, con su nombre completo así: "Xptoval de Villalpando Fac"'.

Para la descripción anterior hemos utilizado un ordenamiento según el criterio de poner primero los episodios reales o milagrosos que corresponden a la vida terrenal de San Francisco y que van del uno al diez, los siguientes que se refieren a hechos milagrosos acaecidos después del tránsito terrenal del santo, van del once al catorce. No está por demás recordar que el señor J. Humberto Castellanos menciona que las pinturas de la vida de San Francisco eran quince, lo que implicaría que había cuatro en la iglesia de San Francisco, habiéndose extraviado una de ellas de 1945 pära esta fecha.

Ya decíamos antes, que casi seguramente quien menciona por primera vez a un pintor Villalpando en nuestro país fue don Jesús Fernández a quien no le adjudica ningún nombre y supone guatemalteco. Es evidente que el señor Fernández tiene un error pero de absoluta buena fe, como puede sucedernos a cualquiera, sin por otra parte, ponerse a inventar mitos. He allí la gran diferencia entre una persona de buena fe y las otras dos, quienes por otra parte tomando sus datos se olvidan de mencionar su origen. ${ }^{28}$ Ese autor fue encargado junto con el Padre Manuel Salvador Castañeda Muñoz, por parte del doctor Eduardo Albores, gobernador del arzobispado, de organizar la participación de éste en la Exposición Centro Americana de $1897,{ }^{29}$ seleccionado entre otras obras El bautizo de San Francisco de Cristóbal de Villalpando, con lo que tenemos la certeza de otro tema incluído en la serie de San Francisco, asimilando la escena a la bíblica, incluyendo la adoración de los magos, según Fernández.

${ }^{28}$ Del aludido periódico La semana católica de los meses mayo y junio de 1897 to maron Díaz y Villacorta sus datos iniciales, pero cuidando de recordar esto no lo citaron, para ser ellos los héroes únicos en la creación de la ficción de Francisco de Villalpando.

${ }^{29}$ Anónimo Datos biográficos del M.I. Señor Arcediano de esta S.i. Catedral Metro palitana Br. don Manuel Salvador Castañeda y Muñoz Guatemala, Tipografía Sánchez \& de Guise, 1919 p.p. 89 
Podemos imaginar fácilmente algunas otras escenas que seguramente estaban incluídas en esta serie franciscana, como por ejemplo el entierro de San Francisco, la aparición del serafín con seis alas como crucifijo ligada a la impresión de las llagas, así como alguna escena en que aparecieron San Francisco y Santa Clara y otra en que se viera el encuentro entre Santo Domingo y San Francisco, entre las principales que nos hacen dolernos de la pérdida de esta secuencia pictórica de la vida de San Francisco, así como de su inspiradora, existente en el convento de San Francisco de México.

Recientemente ${ }^{30}$ fue encontrada por Elisa Vargas Lugo y Marco Díaz, en Huaquechula, Puebla, una serie de la vida de San Francisco hecha por el pintor poblano Luis Berrueco, activo entre los años 1717 y 1750 . No cabe duda de que Berrueco manifiesta tener cierta influencia de Villalpando y Correa, y resulta particularmente interesante observar comparativamente las pinturas de San Francisco de Guatemala con las de Huaquechula, porque si bien algunas son claramente distintas en sus fuentes de inspiración hay otras en que se ve perfectamente una influencia de Villalpando o quizás del modelo que éste debió tomar de Echave Ibía, que probablemente también Berrueco conoció. Así, notamos la presencia de elementos de orfebrería tan característicos en la obra de Villalpando, que Berrueco incluye una exhibición de ella en El Bautizo de San Francisco que muestra una clara semejanza con el lienzo El sueño del Papa Gregorio IX, que se encuentra en el Museo Colonial; igualmente en La muerte de San Francisco, tanto en la composición, pero primordialmente en el detalle del recipiente de plata que aparece en primer plano se ve una clara semejanza con Villalpando, como también en el San Francisco predicando, de Berrueco cuya figura principal es muy parecida a la que se le ha llamado San Francisco y el Apocalipsis, de la serie guatemalteca. En cambio en El Capítulo de las esteras se ve una solución compositiva totalmente dis. tinta. También vale la pena señalar por medio de la serie franciscana de Berrueco otros temas posibles, ahora faltantes en la secuencia de Guatemala, como son Predicación de San Francisco, La instauración del pesebre, Expansión de la obra franciscana, El Papa Nicolás $V$ ante el cadáver de San Francisco, San Francisco en la zarza, Alegoria de la Inmaculada Concepción, La visión de la redoma, y Profesión de Santa Clara. De igual manera probablemente la serie de Guatemala podría servir para imaginar otras escenas faltantes en la serie de Berrueco.

30 Vargas Lugo y Díaz Marco, obra citada 


\section{Otras pinturas de Cristóbal de Villalpando en Guatemala}

Ya hemos afirmado que también se han perdido los otros dieciséis lienzos pequeños hechos por Villalpando, aunque quizás pueda ser parte de ellos uno con el tema de La muerte de San José, $(1.62 \mathrm{~m}$. alto $\times 1.05 \mathrm{~m}$. ancho), que perteneció a don Alberto Zamudio y que actualmente se encuentra en manos de otro coleccionista privado. En el cuadro podemos apreciar al santo en su lecho de muerte, teniendo a su lado derecho a Jesús, suavemente consternado; a su izquierda a la Virgen María, quien también se le ve adolorida y vuelve su rostro hacia el espectador, en el lado izquierdo en primer plano, se ve un arcángel que lleva una palma y entre éste y Jesús se ve lo que parece ser un ángel de la guarda. Está firmado, como los de Ja vida de San Francisco con el usual "Villalpando Fact".

Existe otra pintura del mismo tema, en la Colección de don Humberto Garavito, que aunque no está firmada tiene tal similitud con la anterior, que creemos poder afirmar, como lo hizo De la Maza, que es del mismo pintor mexicano, aunque de mediana calidad. Los cambios fácilmente observables son los siguientes: Jesús y la Virgen han intercambiado su posición respecto del cuadro anterior; en la parte superior hay un semicírculo de querubines y en el centro de éste se encuentra el Espíritu Santo. Luce esta pintura una cama con dosel con cortinajes de tela gruesa, uno de los cuales, al caer, ocupa el sitio en donde se encuentra el arcángel en la otra pintura, así como una pequeña mesa con una tasa de china, un frasco de cristal y otro recipiente probablemente con medicinas, y esta obra lleva además, un pequeño angelito, como los niños que tan frecuentemente coloca Villalpando en primer plano, que lieva la vara con azucenas características de San José (mide la pintura $1.95 \mathrm{~m}$. alto $\times 1.28 \mathrm{~m}$. ancho) ${ }^{31}$

Señalábamos antes que en la iglesia de San Jerónimo, Baja Verapaz, habíamos localizado otra pintura de Villalpando, se trata de una Virgen de Gudalupe $(1.65 \mathrm{~m}$. de alto $\times 1.10 \mathrm{~m}$. de ancho, aprox.), que forma parte de un retablo. Siendo una copia de la pintura aparecida milagrosamente en México, no podemos pretender encontrar mucha originalidad en esta que también va firmada "Villalpando $F^{t "}$. Dice de La Maza" que Villapando pintó por lo menos una Virgen de Guadalupe que se conserva en Sevilla, a la que debemos añadir esta obra en Guatemala. Vale la pena mencionar que a partir de 1648 cuando describe el prodigio guadalupano el Bachiller Miguel Sánchez, se popularizó rápidamente el culto guadalu-

31 De la Maza, 1964, p. 149

${ }^{32}$ De la Maza, 1964, p 128 
pano, siendo Juan Correa el primero en hacer una calca del original, la que muy posiblemente utilizó Villalpando, siendo amigo y colega de aquel pintor. Posteriormente hicieron innumerables copias, las cuales fueron en su mayoría enviadas a España en donde según parece hay más de tres mil, pero existen en gran cantidad en Iberoamérica también. La diferencia entre las dos guadalupanas hasta ahora conocidas en Villalpando, estriba en que la que se encuentra en Sevilla tiene los cuatro medallones con escenas del Tepeyac, en cambio la de Guatemala se ciñe más al original pues carece de estos medallones. De cualquier manera es muy posible que sea la representación más antigua existente en Guatemala de la Virgen de Guadalupe. Curiosamente es óleo sobre tabla.

En el Palacio Arzobispal en la ciudad de Guatemala, existe una pintura de los Desposorios de la Virgen, que aunque tampoco se encuentra firmada si no es de Villalpando, es una copia muy fiel de dos pinturas que con el mismo tema están en México, una en el Museo del Carmen, en San Ángel, que es la más parecida por sus proporciones, y la otra en la Pinacoteca Virreinal, de forma apaisada y con dos arcángeles de cada lado, flanqueando a San José y la Virgen, pero cuya escena central es básicamente la misma que la anterior. La pintura del Palacio Arzobispal tiene como diferencia respecto de las dos antes aludidas, que detrás de la Virgen aparecen tres figuras de acólitos, dos de los cuales llevan ciriales de plata. Otra pintura muy similar a ésta se encuentra en la iglesia de San Juan Comalapa, Chiltenango, según observación del investigador Ricardo Toledo Palomo, con la diferencia que San José ocupa el lugar que en las otras tiene el sacerdote, el que se encuentra a la izquierda en esta pintura, pero el fondo arquitectónicu, así como las flores en el suelo recuerdan mucho el estilo de Villalpando. ${ }^{33}$ Esta también tiene gran semejanza con una pintura del mismo tema de Sebastián López de Arteaga (1610-ca 1656), uno de los mejores discípulos de Zurbarán, quien llegara a México hacia 1635, en donde falleciera, tela que se encuentra en la Pinacoteca Virreinal de la capital mexicana.

Hemos localizado otra posible pintura atribuible a Villalpando en el convento de San Francisco en la ciudad de Guatemala, en donde existe una pintura, como es usual en tales establecimientos, en la escalera del claustro bajo al alto, con el tema de la Inmaculada con las características del llamado Triunfo de Escoto: la figura central es la Virgen María quien

33 Infortunadamente no hemos podido estudiar la pintura ya que debido al terremoto de 1976 las obras de atte de la iglesia de Comalapa se encuentran en una bodega en condiciones que imposibilitan ser vistas. 
lleva en su mano derecha un látigo con una filacteria que dice: "El V. Subtil Dr. Escoto" y en la siniestra unas riendas con las que dirige a un dragón: cada cabo de la rienda lleva respectivamente la leyanda "Philipo IV" y "Religión Seráfica" y a manera de freno con "Alejandro VI" en la parte inferior lleva además una estrofa que dice:

Sentada ya mi pureza

con este nuevo bocado

del antiguo he descuidado

La pintura mide $2.66 \mathrm{~m}$. alto $\times 1.63 \mathrm{~m}$. ancho, tiene ciertos detalles que nos recuerdan claramente a Villalpando, particularmente unas pequeñas figuras de Adán y Eva con los defectos anatómicos y las actitudes gesticulantes de los brazos, tan característicos de ese pintor. Dado que se alude a Felipe IV quien reinara de 1621 a 1665, bien podría cronológicamente hablando ser obra de nuestro pintor, así como el hecho de estar en un convento y en un sitio tan relacionado con el lugar preciso que se le asignara a los cuadros pedidos a Villalpando. Desgraciadamente no está firmada la pintura que se nota en bastante mal estado.

En todo caso, lo anterior nos hace pensar en la posibilidad de haber existido otras pinturas de Cristóbal de Villalpando, además de las cuarenta y nueve consignadas en el contrato, ${ }^{34}$ en el Reino de Guatemala. Por lo que opinamos que una cuidadosa búsqueda pudiera dar interesantes resultados en lo que respecta a la presencia de más pinturas mexicanas en Guatemala y el resto de Centro América.

Resulta curioso anotar que hasta ahora no se han encontrado obras pictóricas firmadas por artistas poblanos, lo que nos indica una contradicción en lo que atañe a los más intensos vínculos entre Santiago de Guatemala y Puebla de los Ángeles en otros aspectos culturales, tal como sucede en la arquitectura colonial, por ejemplo. ${ }^{35}$ Es evidente que las pinturas identificadas como de origen mexicano, todas proceden de talleres de artistas conocidos en la ciudad de México, tales como Cristóbal de Villalpando, Juan Correa, Pedro Ramírez y Miguel Cabrera entre los prin-

${ }^{34}$ El aludido Toledo Palomo recuerda haber visto en la sactistía de la iglesia de San Francisco en esta ciudad, una pintuta con el tema de la "Imposición de las llagas a San Francisco", de menotes dimensiones que las conocidas de la setie franciscana: acaso de esta tomó modelo el autor de la de igual tema que se encuentra en la iglesia de Santo Domingo de esta ciudad.

35 Angulo Iñiguez, Diego, Historia del Arte Hispanoamericano. Barcelona Salvat Editores, S.A, 1950. Tomo II p. 417. Según este autor se nota la influencia de Rubens y dicho lienzo está en la iglesia parroquial de San Miguel, México, D. F. 
cipales. También resultaría interesante hacer un análisis de la influencia de Villalpando en la pintura guatemalteca, lo cual merecería un artículo especial, por lo que nos conformamos con indicar que nos parece percibir la misma en algunas obras de Tomás de Merlo, así como en diversos arcángeles, sin autor conocido, que se encuentran diseminados en distintas iglesias y colecciones privadas en Guatemala.

Igual cosa se podría decir respecto de los antecedentes estilísticos de Villalpando, como los ya señalados con los Echave Otio e Ibía, López de Arteaga y estos que ahora incluímos con Pedro Ramírez (activo 1650-78) y José Juárez (ca 1620-ca 1665). El primero tiene un lienzo denominado Jesús consolado o asistido por los ángeles, que nos recuerda mucho el que hemos llamado Cena Eucarística de San Francisco, con la diferencia que el de Ramírez no tiene a San Francisco de Asis y tiene varios arcángeles en vez de los pequeños ángeles que tiene el de Villalpando. ${ }^{36}$ Una versión más popular del mismo, con Jesús y San Francisco se localiza en una colección privada según indicación de Ricardo Toledo Palomo, ${ }^{37}$ lo cual vendría a ser un ejemplo de cómo la pintura de Villalpando pudo difundirse al tomársele como modelo. Respecto de José Juárez, tiene una pintura titulada Milagro de San Francisco, que se encuentra en la Academia de Bellas Artes de San Carlos, en México, que recuerda mucho el estilo de Echave Ibía, y en uno de cuyos ángulos se encuentra una exhibición de piezas de orfebrería que recuerda bastante la de El sueño del Papa Gregorio II, de Villalpando, en el Museo Colonial de Antigua Guatemala. ${ }^{38}$

Recientemente, según una publicación de la distinguida restauradora Ángela Camargo, ${ }^{39}$ ha creído localizar tres pinturas atribuídas a Cristóbal de Villalpando: Adoración del Niño, San Juan Bautista y la Muerte de San losé, todas con las mismas dimensiones ( $1.24 \mathrm{~m}$. alto y $0.99 \mathrm{~m}$. ancho), así como dos pinturas atribuídas a Juan Correa, otra a Miguel Cabrera y catorce pasos de Viacrucis de Joseph de Ovalle. Lamentamos discrepar

36 Colección de don Catlos Weissenbetg.

${ }^{37}$ Hemos tenido oportunidad de constatar los intensos vínculos comerciales y culturales entre estas dos urbes, los cuales están esbozados en: Luján Muñoz, Luis: "Apuntes sobre las relaciones entre Santiago de Guatemala y Puebla de los Ángeles en la colonia", Antropología e Historia de Guatemala, Vol XX. No. 2 (julio-diciembre 1968, Guatemala, Instituto de Antropología e Historia, pp. 33.39

${ }^{38}$ Esto vendría a indicar, como parece señalarnos el caso de Luis Berrueco, que la secuncia de la vida de San Francisco de Asís hecha por Echave Ibia ejerció bastante influencia al ser tomada como modelos por varios pintores. Angulo Iñiguez 1950, p. 142 fig. 363.

${ }^{39}$ Camargo, Ángela, Orosi, México, edición de la Organización de Estados Americanos, 1980 . 
con nuestra distinguida amiga Camargo, pero nos parece muy improbable que tal conjunto de pinturas novohispánicas se encontraran en Orosi, en el confín del Reino de Guatemala, siendo que apenas lo tendrían algunas de las iglesias más importantes de la ciudad de Santiago de Guatemala. Sin pruebas documentales a favor de su origen mexicano, más nos inclinamos a creer que son pinturas de origen guatemalteco de la época barroca, correspondiente al siglo XVIII, sin que descartemos en ellas posibles influencias mexicanas o españolas, que naturalmente existían en la pintura colonial guatemalteca: por otra parte no debemos olvidar la posibilidad de la influencia de grabados de diversa procedencia a través de la distancia. Además, Villalpando usualmente firmaba sus pinturas y la de la Muerte de San José, es baștante distinta, sobre todo el colorido, de las que se conocen en Guatemala y a las que ya nos referimos. Asimismo, nos parece ilógico que una pequeña misión, aunque muy bella e interesante, construída a mediados del siglo XVIII (ca. 1766) tuviera pinturas de autores que pertenecían cronológicamente a finales del siglo XVII y a principios del XVIII como serían Correa y Villalpando. Es decir, que concluiríamos diciendo, que tanto la escultura, como la pintura y la platería de Orosi nos parecen đe origen guatemalteco, no así los retablos que, de acuerdo con la valiosa publicación de Ángela Camargo, son de procedencia sudamericana, preferentemente neogranadina.

Recapitulando creemos que no debemos ser excesivamente exigentes respecto de la desigualdad del conjunto que existe en Guatemala sobre La vida de San Francisco de Asís, ya que Villalpando debió sujetarse a dos condiciones básicas: la primera, tomar como modelo las pinturas que con igual tema había hecho Baltasar de Echave Ibía hacía 1649, que se encontraban en el Convento Grande de San Francisco en la ciudad de México y que evidentemente impresionó mucho a los frailes guatemaltecos, pero de la cual serie no ha quedado rastro alguno, aunque se vean ciertas similitudes con el tipo físico franciscano y los fondos de paisaje pintados por los Echave, que han subsistido. En segundo lugar, debió someterse a las dimensiones y ordenamiento requeridos por las características de los claustros bajo y alto del Convento Grande de San Francicso de Guatemala, como puede observarse en la pintura San Francisco y la tempestad, cuya composición obviamente hubiera requerido una proporción apaisada para no deformar la embarcación, como debió hacer Villalpando para mantener la secuencia ordenada por los franciscanos de Guatemala.

Finalmente, esperamos que con la publicación y análisis del contrato entre Villalpando y los franciscanos de Guatemala, así como dar a pu- 
blicación por primera vez las fotografías de las diecinueve obras conocidas de dicho pintor en Guatemala, hayamos contribuido a complementar el catálogo de las obras de Cristóbal de Villalpando y a puntualizar más acerca de un aspecto del intercambio cultural entre el Reino de Guatemala y la Nueva España, relacionado con este importante artista novohispano, tan imbuído del signo barroco de su época. 


\section{APENNDICE DOCUMENTAL}

Contrato para hacer cuarenta y nueve pinturas efectuado entre Cristóbal de Villalpando y el Convento de San Francisco de la ciudad de Guatemala.

En la ciudad de México, a veinte de septiembre de mill seisstos y uuventa y un años, ante mí escribano y testigos, parecieron de la una parte Xptoval de Villalpando, Maestro pintor, y de la otra Franco Gómez del Corral, mercader, vecinos desta ciudad, a los cuales doy fe conosco. Otorgan que están convenidos y concertados el uno con el otro y por la presente se obliga el dicho Maestro Xptoval de Villalpando de hacer treinta y tres liensos grandes y dies y seis chicos con la vida de N.S.P.S. Franco, conforme está la del claustro del Convento principal desta Ciudad de México, de suerte que todos sean cuarenta y nueve liensos, todos de pincel, conforme el mapa que se remitió de la Ciudad de Goatemala por el Muy R.P. Fray Franco de Suassa y Otalora, del orden de San Franco y Provincial de aquella provincia, por cuya disposición y en virtud de horden hace el dicho conocierto el dicho Francisco Gómes del Corral, por carta firmada del dicho R.P. Fray Franco Suassa, su data en Goatemala a veinte y cinco de agosto pasado deste presente y dicho año. En cuya virtud (h) a hecho el dicho concierto con el dicho Maestro Xtopval de Villalpando, quien se obliga de hacer de pincel los lienzos grandes y pequeños que van expresados y se refieren en el dicho mapa remitido de Goatemala, firmado de ambas partes y rubricado de sus manos el presente año, por el cual se (h) a de dictar y pasar. Por cuyo travaxo, materiales, lienso y paga de oficiales esta concertada dicha obra en dos mill, nuevecientos y sessenta pesos. Los un mill pesos de ellos que le paga adelantados el dicho Francisco Gómez del Corral, de quien los (h) a recibido en reales de contado el dicho Xptoval de Villalpando, de los cuales se da por entregado, renuncia leyes de la pecunia y su prueba y otorga carta de pago en forma. Otros quinientos pesos que se le (h) an de satisfacer en el discurso del plaso de dicha obra y los un millcuatrocientos y sessenta pesos restantes que se le (h) an de satisfacer el día que la diere acavada. Se obliga el dicho Xptoval de Villalpando a que para de (h) oy día de la fecha de esta carta en un año primero siguiente (h) abrá entregado con toda perfección y según arte, la obra compuesta de los liensos de pincel que van expressados conforme a la del claustro del Convento principal de San Franco desta Ciudad y se expresaran en el mapa remitido de la dicha Ciudad de Goate- 
mala, aparejando los liensos con toda perfección según arte, para su permanencia y dándole al pincel todo el primor que pudiera para su realsse y mexor perfección, estando todo ello a contento y satisfacción de dos Maestros que lo entiendan. $Y$ por defecto de no dar acavada la dicha obra al fin del plasso de dicho año que cumplirá el veinte de septiembre del que viene de mill seiscientos y noventa y dos años o que no esté de dar y resevir según arte y a satisfacción de Maestros que lo entiendan, da facultad al dicho Franco Gómes del Corral para que se pueda concertar con los maestros del arte que le pareciere para que la acaven dicha obra en la forma expresada. Y por lo que más le costare de los dos mill nuevecientos y sesenta pesos de su concierto, que deja diferido en su declaración simple, sin otra prueba de que le releva, se lo pagará. $Y$ por lo que fuere y montare y por los dichos un mill pesos que al pressente (h) a resevido de contado y por los demas que en adelanta constare (h) aver resevido se le pueda executar como por deuda líquida y al plasso passado con las costas de la cobranza.

Y el dicho Franco Gómez del Corral en conformidad del orden expressado en la carta de suso sitada de dicho R.P. Provincial Fray Franco de Suassa, declara que (h) a hecho el concierto de dicha obra con el dicho Maestro Xptoval de Villalpando, en los dichos dos mil nuevecientos y sesenta pessos, $\mathrm{y}$ en su complimiento le tiene entregados los mil pesos de ellos, según va referido, procedidos de los un mill quinientos pessos que el dicho Franca Gómez del Corral, cobró del Alférez Andrés Fernández de la Torre, vezino desta ciudad, en virtud de libransas para este efecto se le remitieron de la dicha Ciudad de Goatemala, según se expresa en dicha orden y carta que queda en su poder para su resguardo. $Y$ se le obliga el dicho Franco Gómes del Corral de resevir la dicha obra al fin del plasso de dicho año, estando con toda perfección acavada y a satisfacción de Maestros que lo entiendan y de pagar al dicho Maestro Xpotval de Villalpando o a quien su poder (h) ubiere y su derecho le pressentare los dichos quinientos pessos en el discurso del plasso del dicho año. $Y$ assimismo se obliga de pagar al dicho Mro., o a quien el dicho poder (h) ubiere los un mill quatrocientos y sessenta pessos de los dos mill nuevecientos y sessenta pessos de su concierto, en reales de contado, en esta ciudad o en otra parte que se le pidan, el día que diere acavada toda la dicha obra, porque se le pueda executar como por deuda líquida y del plasso passado con las costas de la cobranza. Y para la primera paga y cumplimiento de todo lo que dicho es, ambas partes, cada una por lo que toca obliguen sus perssonas y bienes ( $h$ ) avidos y por ( $h$ ) aver y con ellos se someten a las Justicias de su Magd de cualesquiera parte, en especial a las desta 
Ciud, Corte y Real Audienzia de ella, renuncian su fuero y la ley si convinerit para que todo rigor de derecho en vía executiva les compelan al cumplimiento, paga y execución desta escriptura, como si fuesse sentenzia definitiba passada en cosa jusgada, renuncian leyes de su favor y la general del derecho y la firmaron testigos Juan Lópes, Juan del Castillo y Fernando Veedor... Real, Vesno de México. Entre renglones: De suerte que todos sean quarenta y nueve liensos: Vale, $\mathrm{Y}$ assimismo se obliga de hacer otros dies y seis liensos más. No vale tillannos (?)

Xptoval de Villalpando

Franco Gómes del Corral

Ante mí.

Martín del Río

Escribano Real y Público.

* Se ha conservado la ortografía del original, únicamente se ha variado levemente la puntuación.

(Archivo de Notarías de la Ciudad de México. Notario Martín del Río, no. 563. Libro del año 1691, fols. 415-16). 